\title{
Performance of NMC's Regional Models
}

\author{
NORMAN W. JUNKER, JAMES E. HOKE AND RICHARD H. GRUMM \\ National Meteorological Center, NWS, NOAA, Washington, D.C.
}

(Manuscript received 4 March 1989, in final form 4 May 1989)

\begin{abstract}
This paper details the performance characteristics of the two regional dynamical models used at the National Meteorological Center to forecast for North America. Strengths and weaknesses of these models-the limitedarea fine-mesh (LFM) model and the nested grid model (NGM) of the Regional Analysis and Forecast System (RAFS) - are presented in terms of their ability to predict such fields and features as 500 -mb heights, surface lows and highs, precipitation events, and the diurnal cycle. The systematic characteristics of the models are emphasized.

Overall, the NGM was found to be more accurate than the LFM. Nevertheless, the LFM is a valuable forecast model because of its accuracy and longevity in providing operational guidance.
\end{abstract}

\section{Introduction}

Weather prediction guidance is provided by the $\mathrm{Na}$ tional Meteorological Center (NMC) based, in part, on the forecasts of two regional models, the limitedarea fine-mesh model (LFM) and the nested grid model (NGM) of the Regional Analysis and Forecast System (RAFS). This paper summarizes many of the characteristics of these models, focusing on systematic model performance and highlighting their strengths and weaknesses. The overall production suite of which these models are a part is described by Petersen and Stackpole (1989) in an accompanying article. Design of the NGM and the other components of the RAFS are presented in Hoke et al. (1989). It should be noted that, although the NGM is referred to throughout this paper; strictly speaking the references should be to the RAFS, which is the complete system of analysis, initialization, and NGM prediction. Two companion papers (Kanamitsu 1989; White and Caplan 1989) describe the design and performance of NMC's global spectral model, referred to throughout this paper as AVN/MRF because it provides aviation and medium-range guidance.

\section{Performance of the LFM}

The LFM is the oldest of NMC's operational numerical models transmitted to users outside NMC. It replaced the barotropic-mesh model as the first operational model run within NMC's 12-h production cycle. The model offers forecasters an early look at how weather systems may evolve and is often used to judge

Corresponding author address: Norman W. Junker, NMC, W/NMC 35, Rm. 402, Washington, D.C. 20233. whether previous model runs still look reasonable. The LFM is also the basis for the MOS (model output statistics) guidance discussed elsewhere in this issue (Carter et al. 1989). The LFM will continue to be run at least until similar statistics can be generated from the NGM. Being the oldest, the model probably has the best documentation of its characteristic errors.

The model was first run in 1972 using a 190.5-km horizontal grid spacing with six layers in the vertical. The model was developed as a higher-resolution version of the hemispheric forecast model at that time, the sixlayer primitive-equation model of Shuman and Hovermale (1968). By 1977 an improved physics package was introduced along with a reduction in mesh length to $127 \mathrm{~km}$. The LFM was restored to its original 190.5 $\mathrm{km}$ mesh length in 1981 with the introduction of fourth-order finite differencing. The forecast model has not been changed since the handling of surface stress was altered in January 1985 (Deaven 1985).

\section{a. Temperature and height prediction}

As a rule, the LFM forecasts of temperature and geopotential height verify worse than those of the NGM. As shown in Table 1 for March-May 1988, mean and standard deviation errors were larger for the LFM at most levels and at most time ranges. The best performance of the LFM relative to the NGM is for 850-mb temperature, where the NGM is handicapped by a weaker-than-observed representation of the diurnal cycle in the analysis and a temperature bias problem over the Rocky Mountains. The LFM also is too cold over the Rockies, as the $850-500-\mathrm{mb}$ thickness error in Fig. 1a indicates, but not as cold as the NGM (Fig. 1b). 
TABLE 1. Mean and standard deviation (s.d.) errors of LFM and NGM forecasts of height and temperature for the 3-month period March 1988-May 1988 (Keyser et al. 1988b). Each model was vérified against its own uninitialized analysis at North American land points.

\begin{tabular}{|c|c|c|c|c|}
\hline \multirow[b]{2}{*}{$\begin{array}{l}\text { Pressure } \\
(\mathrm{mb})\end{array}$} & \multirow[b]{2}{*}{$\begin{array}{l}\text { Forecast } \\
\text { model }\end{array}$} & \multicolumn{3}{|c|}{ Forecast time } \\
\hline & & $\begin{array}{c}24 \mathrm{~h} \\
\text { mean } / \mathrm{s} . \mathrm{d} \text {. }\end{array}$ & $\begin{array}{c}36 \mathrm{~h} \\
\text { mean/s.d. }\end{array}$ & $\begin{array}{c}48 \mathrm{~h} \\
\text { mean/s.d. }\end{array}$ \\
\hline \multicolumn{5}{|c|}{ Height Errors (m) } \\
\hline 250 & $\begin{array}{l}\text { LFM } \\
\text { NGM }\end{array}$ & $\begin{array}{r}-18.1 / 32.2 \\
11.2 / 27.7\end{array}$ & $\begin{array}{r}-21.4 / 45.1 \\
13.2 / 38.5\end{array}$ & $\begin{array}{r}-28.8 / 56.3 \\
11.3 / 50.6\end{array}$ \\
\hline 500 & $\begin{array}{l}\text { LFM } \\
\text { NGM }\end{array}$ & $\begin{array}{r}-6.8 / 26.2 \\
2.5 / 21.9\end{array}$ & $\begin{array}{r}-7.5 / 34.5 \\
3.0 / 30.9\end{array}$ & $\begin{array}{r}-12.0 / 43.0 \\
1.6 / 40.0\end{array}$ \\
\hline 850 & $\begin{array}{l}\text { LFM } \\
\text { NGM }\end{array}$ & $\begin{array}{r}-6.4 / 12.1 \\
4.3 / 19.3\end{array}$ & $\begin{array}{r}-7.5 / 26.0 \\
5.2 / 25.2\end{array}$ & $\begin{array}{r}-12.1 / 31.0 \\
5.5 / 30.5\end{array}$ \\
\hline \multicolumn{5}{|c|}{ Temperature Errors $\left({ }^{\circ} \mathrm{C}\right)$} \\
\hline 250 & $\begin{array}{l}\text { LFM } \\
\text { NGM }\end{array}$ & $\begin{array}{r}-0.19 / 2.25 \\
0.22 / 1.48\end{array}$ & $\begin{array}{r}-0.45 / 2.54 \\
0.29 / 1.79\end{array}$ & $\begin{array}{r}-0.65 / 2.83 \\
0.28 / 2.06\end{array}$ \\
\hline 500 & $\begin{array}{l}\text { LFM } \\
\text { NGM }\end{array}$ & $\begin{array}{r}0.10 / 1.41 \\
-0.02 / 1.44\end{array}$ & $\begin{array}{l}0.16 / 1.75 \\
0.02 / 1.76\end{array}$ & $\begin{array}{r}0.19 / 2.10 \\
-0.03 / 2.13\end{array}$ \\
\hline 850 & $\begin{array}{l}\text { LFM } \\
\text { NGM }\end{array}$ & $\begin{array}{l}-0.58 / 2.18 \\
-0.52 / 2.54\end{array}$ & $\begin{array}{l}-0.74 / 2.60 \\
-0.66 / 2.92\end{array}$ & $\begin{array}{l}-0.88 / 2.92 \\
-0.79 / 3.27\end{array}$ \\
\hline
\end{tabular}

\section{b. Performance in predicting synoptic features}

Although the LFM was superior to its predecessors, the barotropic-mesh model and the six-layer primitiveequation model, it nevertheless has some shortcomings in predicting synoptic features. For example, from its inception, meteorologists recognized that the LFM sometimes had a problem forecasting weather systems moving out of the Rockies. The model often lowered $500-\mathrm{mb}$ heights and mean-sea-level pressure too quickly east of the Rocky Mountains. For example, W. Collins (personal communication) observed that a negative height bias often occurred at $500 \mathrm{mb}$ east of the Rockies with an associated eastward mislocation of the mean upper-level trough. This error was maximized during winter, but did not seem dependent on the latitude of the jet. Except for a slight reduction in the bias due to Deaven's (1985) change in the surface stress, this negative height bias continues today.

The impact of this negative height bias at $500 \mathrm{mb}$ on other forecast fields was examined by Junker (1985). He found that 850-mb geopotential height and mean-sea-level pressure were also affected, with the model lowering pressures and heights too quickly east of the Rockies. Sometimes, as a result, dramatic errors in advection patterns and positioning of the low-level southerly jets occurred. Moisture associated with the low-level jet and the associated surface front were moved too quickly eastward across the Great Plains and Mississippi Valley. Heaviest precipitation, there- fore, was observed south and west of where it was forecast by the model. Junker also suggested the error might be larger when the mean upper-level trough was located in the southwestern United States.

The LFM forecasts of cyclones were also examined by Silberberg and Bosart (1982). One of their findings was that the LFM overforecast the number of cyclones downwind of major mountain barriers, with eastern Oklahoma and Arkansas particularly vulnerable to spurious cyclogenesis. They noted that the error in the forecast movement of cyclones changed during the year. Model cyclones were generally too slow in November and October, and too fast during March and April. Over oceanic regions, they found that the LFM generally underforecast the intensity of cyclones. They cautioned, however, that meteorologists should resist making systematic error corrections without a close examination of the meteorology involved in each case, because model errors are often driven by deficiencies in the initial analysis.

Cyclogenesis over Nevada is rarely forecast adequately when an upper trough amplifies or "digs" towards Nevada and moves east of $126^{\circ} \mathrm{W}$ with an upperlevel jet crossing the Sierra Nevada range between $30^{\circ}$ and $40^{\circ} \mathrm{N}$. For example, on 16-17 March 1989 a surface low reformed in northern Nevada and then tracked into southern Utah. The LFM forecasts never showed a surface low south of central Idaho.

The ability of the LFM in predicting explosive cyclogenesis (referred to as a "bomb") in the west-central North Atlantic was evaluated by Sanders (1986). A bomb was defined as a cyclone in which the 24-h deepening rate was $\geqslant 24 \mathrm{mb} /$ day, adjusted for the latitudinal variation in the Coriolis force. He denoted the center of the time period of maximum deepening as time zero and compared the central pressure of the surface lows from the 0-48-h LFM forecasts to the corresponding initial analyses for 48 different storms. Sanders found that the systematic errors in pressure were generally small until the onset of maximum deepening. Significant errors appeared at time zero, steadily growing to about $10 \mathrm{mb}$ for $36-$ and 48 -h forecasts verifying 12 and $24 \mathrm{~h}$ after the onset of maximum deepening. In general, the mean directional error for all time ranges (provided in Table 2) showed an eastward bias; i.e., the LFM generally forecast the bombs too far to the east. While the 12-h forecasts showed a tendency towards forecasting the cyclones too far to the eastsoutheast, all other time ranges showed a bias toward the east-northeast. Thus, the directional error rotated counterclockwise with increasing forecast hour. Because lows along the East Coast of the United States generally move to the northeast, this indicated that the LFM was generally too fast. Sanders also found that the 48-h mean distance error for bombs was $341 \mathrm{~km}$. (We define mean distance error as the mean of the distance between forecast and observed positions, and magnitude of the mean vector position error as the 
(a)

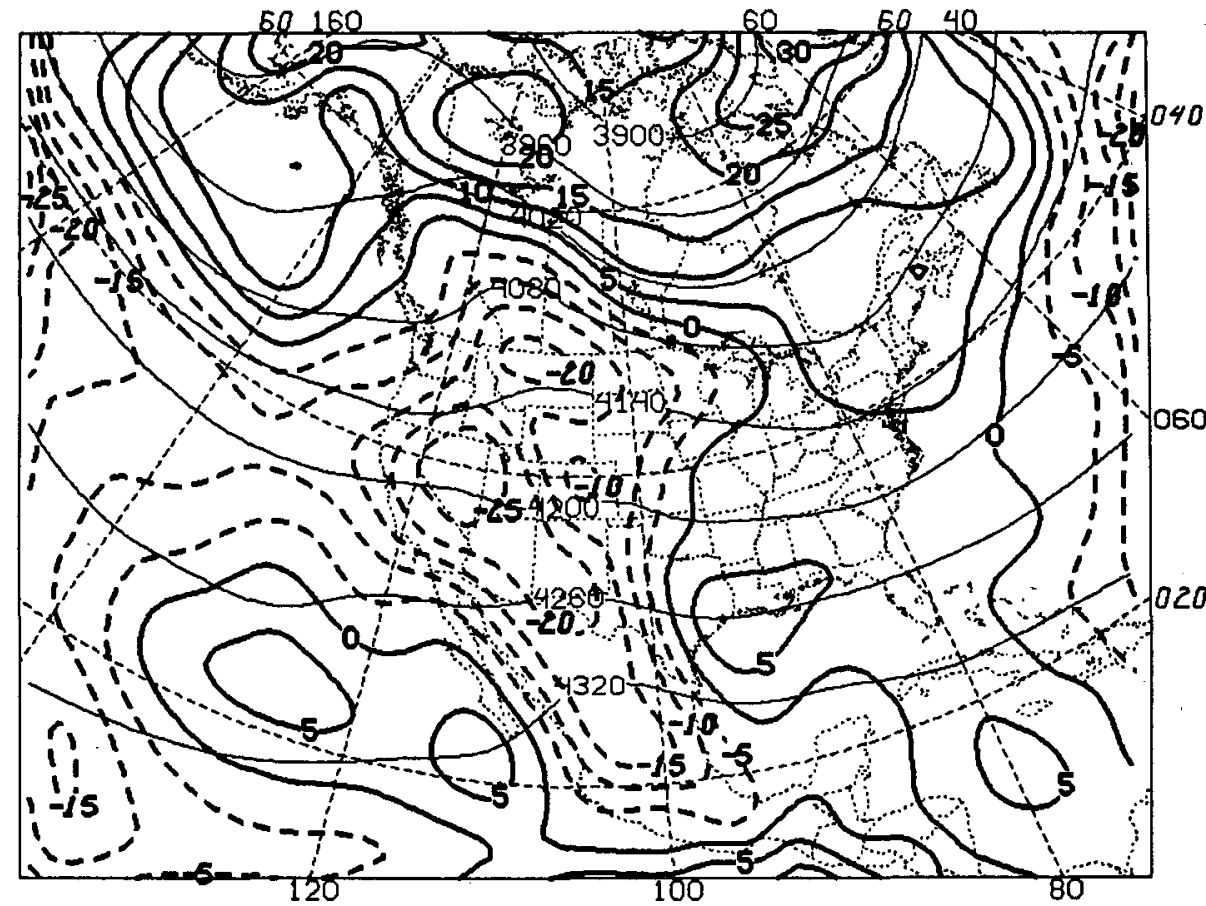

(b)

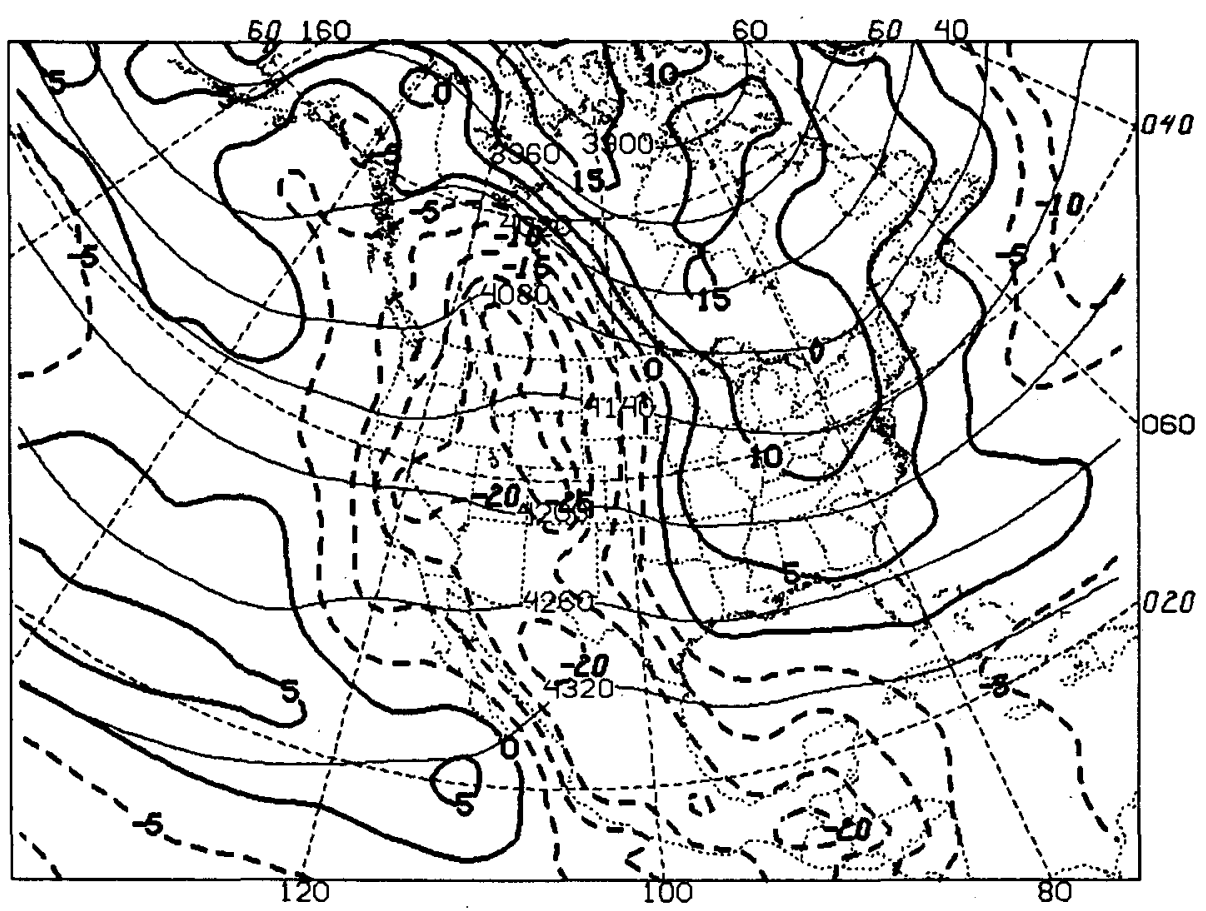

FIG. 1. Mean error (heavy contours) in 48 -h forecasts of $850-500$-mb thickness during the period March-May 1988 for (a) the LFM, and (b) the NGM. Contour interval is $5 \mathrm{~m}$, with negative values dashed. Verification is the analyses of the AVN/MRF (light contours, 40-m contour interval). 
TABLE 2. Mean vector position error in LFM forecasts of lows undergoing explosive cyclogenesis in the west-central North Atlantic (Sanders 1986). The direction of the mean vector position error is from analyzed to predicted position, with $90^{\circ}$ to the east and $180^{\circ}$ to the south.

\begin{tabular}{ccc}
\hline \hline & \multicolumn{2}{c}{ Mean vector position error } \\
\cline { 2 - 3 } $\begin{array}{c}\text { Forecast time } \\
(\mathrm{h})\end{array}$ & $\begin{array}{c}\text { Magnitude } \\
(\mathrm{km})\end{array}$ & $\begin{array}{c}\text { Direction } \\
(\mathrm{deg})\end{array}$ \\
\hline 12 & 64 & 117 \\
24 & 89 & 77 \\
36 & 127 & 67 \\
48 & 130 & 63 \\
\hline
\end{tabular}

magnitude of the vector sum of the vector differences between forecast and observed positions.)

Several studies of LFM forecasts of anticyclones have been made. For example, Grumm and Gyakum (1986) investigated the accuracy of $48-\mathrm{h}$ forecasts of anticyclone centers during the winter of $1981 / 82$ for North America. The LFM analysis was used as verification. Looking at 445 anticyclones, they concluded that the LFM generally underforecast the maximum mean-sealevel pressure of anticyclones, especially east of $100^{\circ} \mathrm{W}$. Additionally, they pointed out that the LFM usually forecasts anticyclone centers too far southeast. The displacement errors were greatest over the eastern United States and adjacent Atlantic, but also occurred over other sections of the United States including the areas off both the East and West coasts. The mean distance error over all cases was $510 \mathrm{~km}$. By shifting anticyclones too far east, return flow developed prematurely around the back side of the surface high. More importantly, the model's tendency to misforecast the position and intensity of anticyclones distorted advection patterns and precipitation forecasts.

Anticyclones over the Gulf Coast were examined by S. Weiss (personal communication) as part of the Gulf of Mexico Experiment in an attempt to determine how well the LFM forecast the return flow on the western side of surface highs. He examined 34 cases from the winter of $1987 / 88$ that involved the movement of continental air into the Gulf of Mexico, followed by the return of moisture inland ahead of an intensifying baroclinic wave. In most cases Weiss found an eastward displacement of surface highs at $48 \mathrm{~h}$, with a mean distance error of $411 \mathrm{~km}$. Because the model was too fast in forecasting the movement of highs eastward, it usually was too fast with the eastern extent of the return flow. Additionally, by $48 \mathrm{~h}$, surface anticyclone centers averaged $8 \mathrm{mb}$ lower than were observed. The errors noted in the LFM were not nearly as pronounced in either the NGM or AVN/MRF.

Weakening of anticyclones over the northeastern United States in the LFM can result in underforecasting the easterly gradient and therefore, negatively impact relative humidity predictions along the East Coast (Dorian 1983). Associated with the weakening is a breakdown in the subsidence over the region.

The LFM's erroneous prediction of surface highs may also contribute to another model weakness. Richwien (1980) found that when a surface high tracked across the northeastern United States, the LFM failed to forecast adequately the damming of the cold air southward along the east side of the Appalachians. This problem may partially stem from the model's tendency to forecast the surface high too far to the southeast, which leads to premature development of onshore lowlevel flow. The failure to predict damming is also probably strongly related to the model's lack of vertical resolution in the lower troposphere.

The LFM has problems handling arctic air masses. Sometimes mean-sea-level pressures are lowered too much in the cold air, the 1000-500-mb layer is warmed, and the surface low tracks too far northwest into the cold air, when, in reality, only a pressure trough forms. Figure 2 shows the 36-h LFM mean-sea-level pressure forecast and verifying analysis valid 0000 UTC 8 January 1988. Note that the LFM underforecasts the mean-sea-level pressure by $15 \mathrm{mb}$ in eastern Tennessee. This type of error happens most often when upperlevel forcing (i.e., vorticity advection) is rather weak.

Limited-area fine-mesh model forecasts of lifted index offer information that can help locate boundaries of shallow cold air (i.e., arctic fronts) in cool season cases from November-April. In these cases, NMC forecasters use the leading (southern) edge of the liftedindex gradient to locate the front instead of the leading edge of the thickness gradient. As shown in Fig. 3a, the 36-h LFM forecast of mean-sea-level pressure and $1000-500-\mathrm{mb}$ thickness indicate a push of cold air into Arkansas and possibly as far south as northern Texas, with the location of the front not clearly defined. The 36-h forecast of lifted index (Fig. 3c), however, clearly shows a strong cold-air outbreak farther south, in better agreement with the verifying analysis (Fig. $3 \mathrm{~b}$ ). The LFM lifted index is often a good indicator of frontal position because it responds strongly to gradients in low-level temperature and moisture in its $50-\mathrm{mb}$ thick bottom layer. The NGM lifted index, on the other hand, is not as useful at highlighting shallow cold-air outbreaks, in part because it is derived from the bottom four model layers (about $185 \mathrm{mb}$ thick).

\section{c. Performance in predicting precipitation}

Model performance in forecasting precipitation is judged at NMC from bias and threat scores for precipitation amounts equal to or exceeding certain thresholds, such as $0.01,0.50$, and 1.00 in. A threshold is defined as a category in which the amount of precipitation at each point equals or exceeds a certain specified amount. For example, for a threshold of 1.00 in., no 
(a)

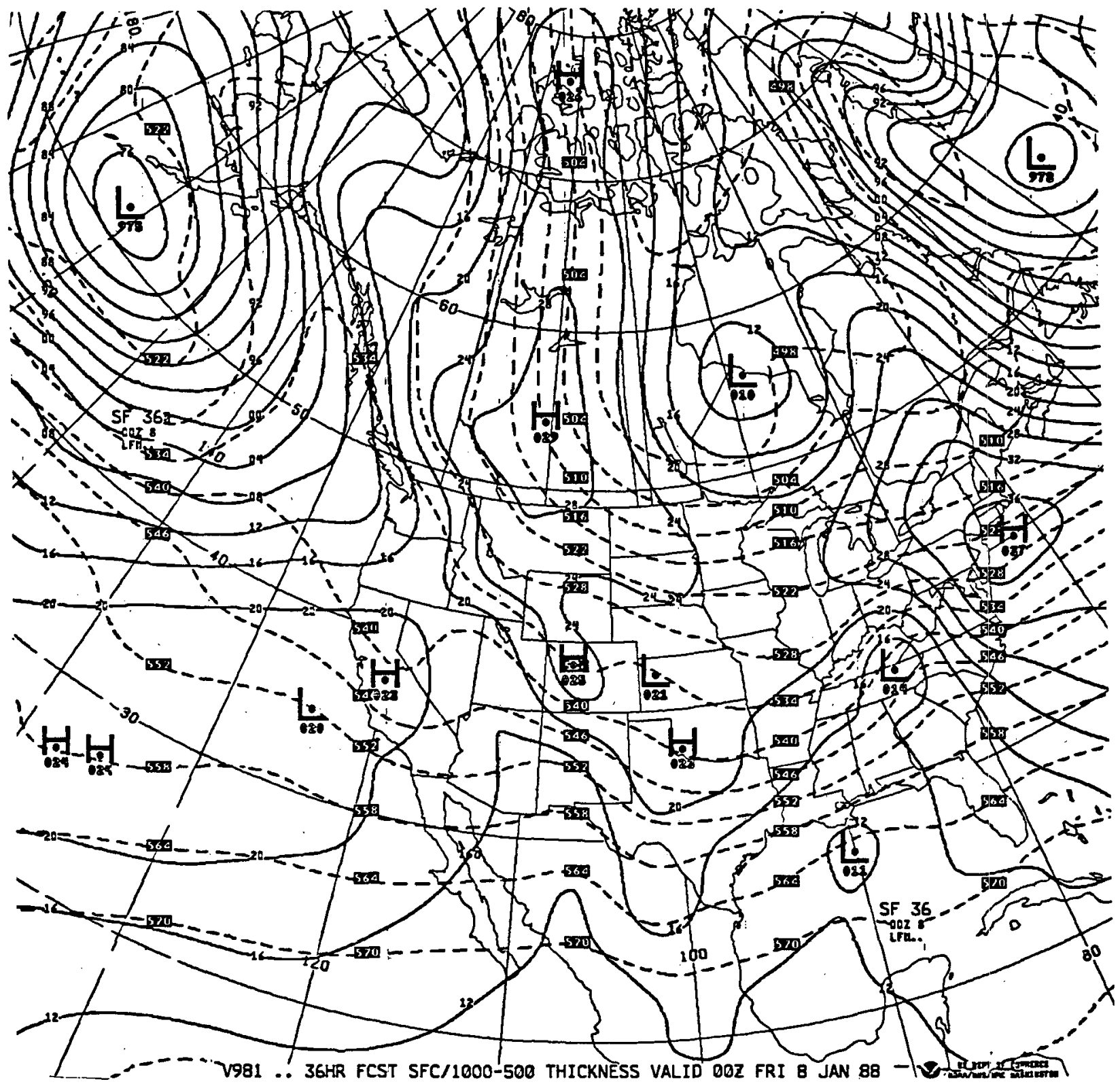

FIG. 2. (a) Thirty-six hour LFM forecast valid 0000 UTC 8 January 1988 , and (b) verifying LFM analysis for mean-sea-level pressure ( solid contours; 4-mb contour interval) and 1000-500-mb thickness (dashed contours; 6-dm contour interval).

points (when verifying against an analysis) or stations (when verifying directly against observations) with values less than $1.00 \mathrm{in}$. are considered.

Bias $(B)$ and threat score $(T)$ are defined as

$$
\begin{aligned}
& B=F / O, \\
& T=H /(F+O-H),
\end{aligned}
$$

where $F$ is the number of stations (or points) forecast to have at least a certain amount (threshold) of pre- cipitation, $O$ is the number of stations (or points) observed to have at least that amount, and $H$ is the number of stations (or points) with correct forecasts for that threshold of precipitation. Bias indicates how well the precipitation amount, but not location, is forecast. When the bias is less (greater) than unity for a given amount of precipitation, the model is underforecasting (overforecasting) the areal coverage for that amount. Threat scores, on the other hand, provide a measure 
(b)

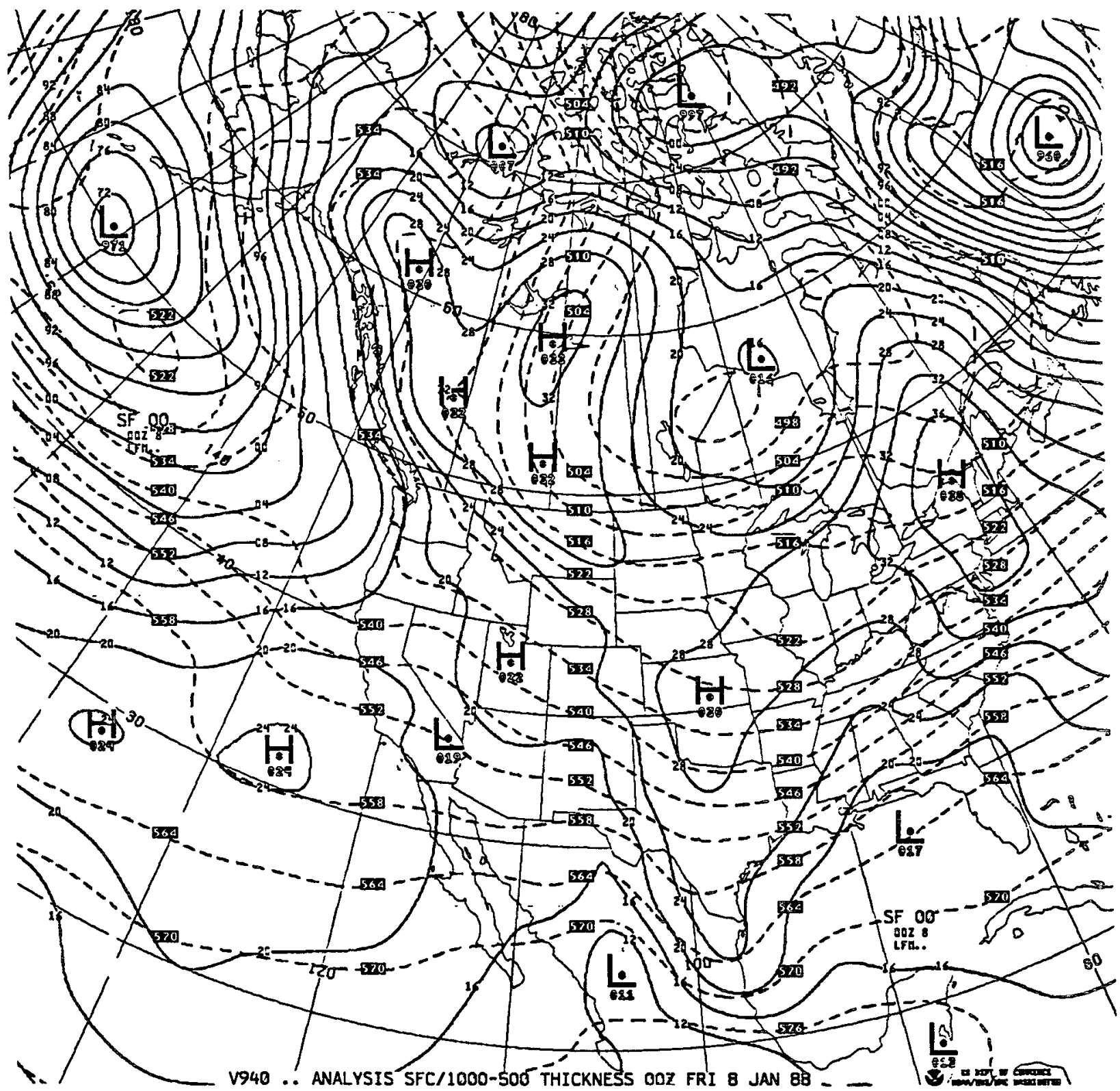

FIG. 2. (Continued)

of how accurately the location of precipitation is forecast. If the number and location of stations receiving a given amount of precipitation are forecast without error, the threat score is 1 . If no stations are correctly forecast, the threat score is zero.

Figure 4 shows the bias of the LFM and NGM for $\geqslant 0.50 \mathrm{in}$. of precipitation in a 24 -h period ending at 1200 UTC from January 1988-February 1989. The forecasts are verified against an analysis of precipitation observations from a high-density precipitation network over the United States east of $107^{\circ} \mathrm{W}$ (Nierow 1985). The grid spacing of the analysis is $31.5 \mathrm{~km}$ at $60^{\circ} \mathrm{N}$ $\left(27.7 \mathrm{~km}\right.$ at $\left.40^{\circ} \mathrm{N}\right)$. The bias of the LFM varies significantly over the course of a year, with overprediction in the cooler part of the year. In summer, however, the bias is considerably less than unity, indicating that the model significantly underforecasts the coverage of heavier precipitation amounts during this season. The model's coarse vertical resolution and weak diurnal cycle contribute to the problem. The LFM's bias is 

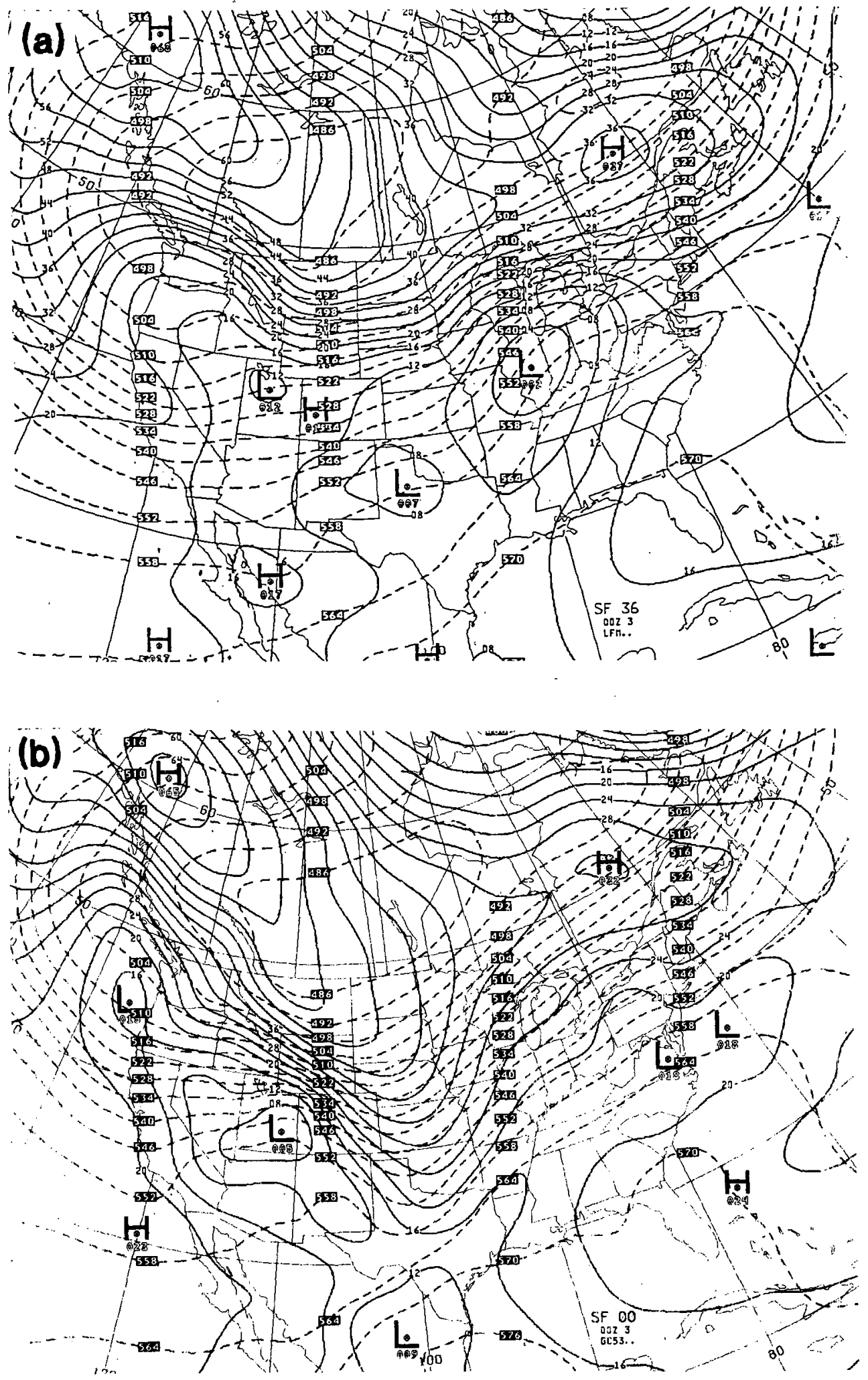

FIG. 3. Mean-sea-level pressure (4-mb contour interval) and 1000-500-mb thickness (6-dm contour interval) at 0000 UTC 3 February 1989 for (a) the operational 36-h LFM forecast, and (b) the verifying; analysis. The 36-h LFM forecast of lifted index valid at 0000 UTC 3 February 1989 is shown in (c) with a contour interval of $4^{\circ} \mathrm{C}$. 


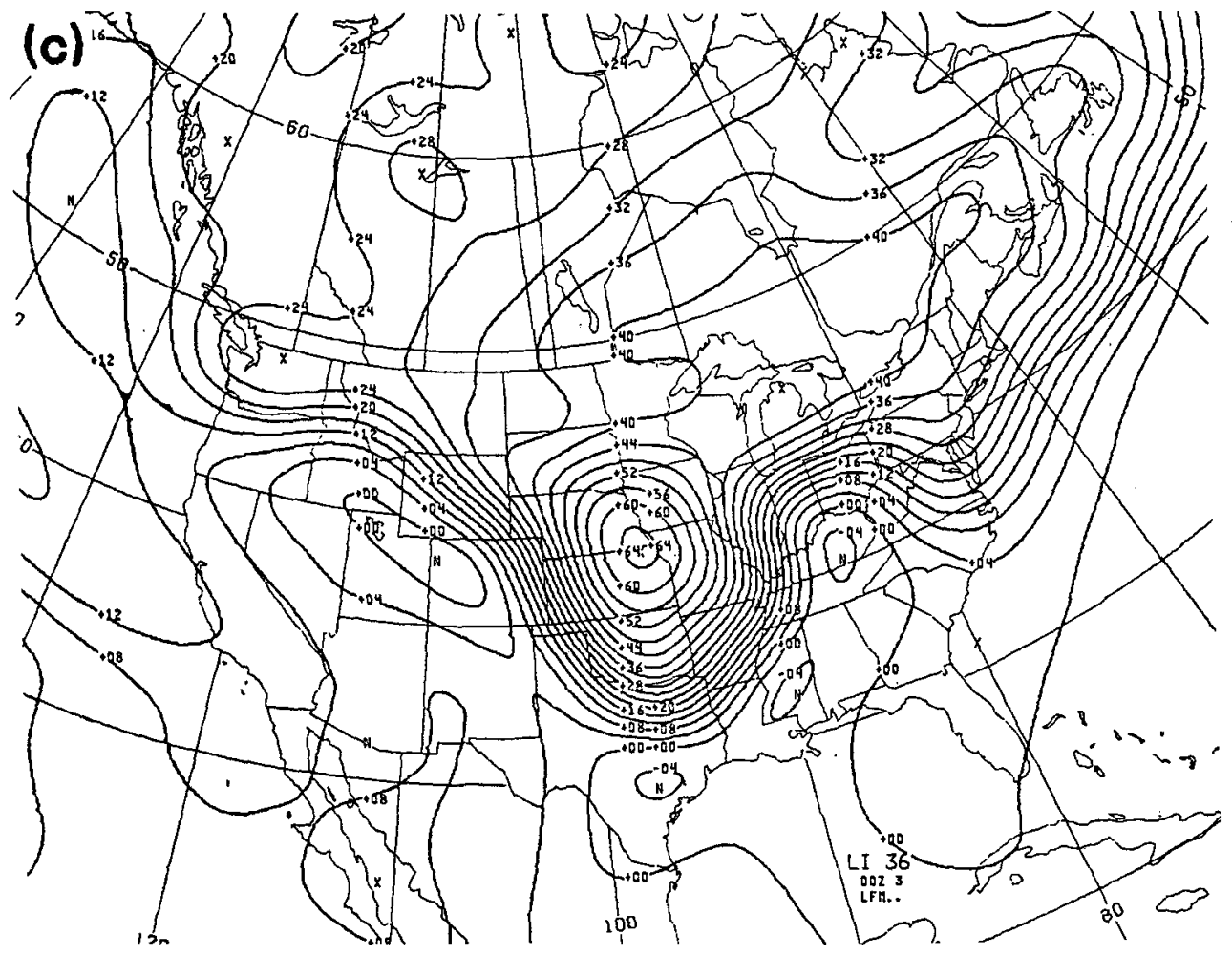

FIG. 3. (Continued)

significantly lower than that of the NGM during summer for heavier amounts $(\geqslant 0.50 \mathrm{in}$.) of precipitation. The LFM generally has lower threat scores than the
NGM for precipitation amounts of $\geqslant 0.50 \mathrm{in}$. during the warm season (Fig. 5), suggesting that the NGM does a better job forecasting heavy convective precip-

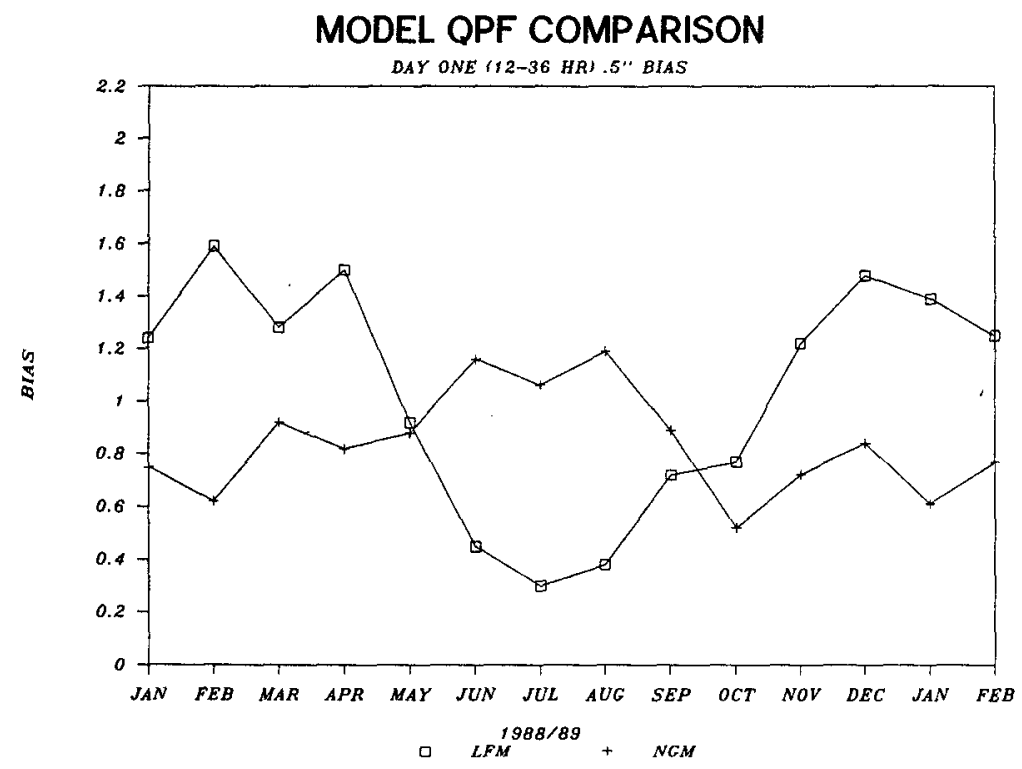

FIG. 4. Bias for LFM and NGM forecasts of $\geq 0.50$ in. precipitation for the $24-h$ period (12-36 h of the model forecasts) valid at 1200 UTC for January 1988-February 1989. Verification is a $31.5-\mathrm{km}$ resolution analysis of precipitation observations from an extensive network over the United States east of $107^{\circ} \mathrm{W}$. 


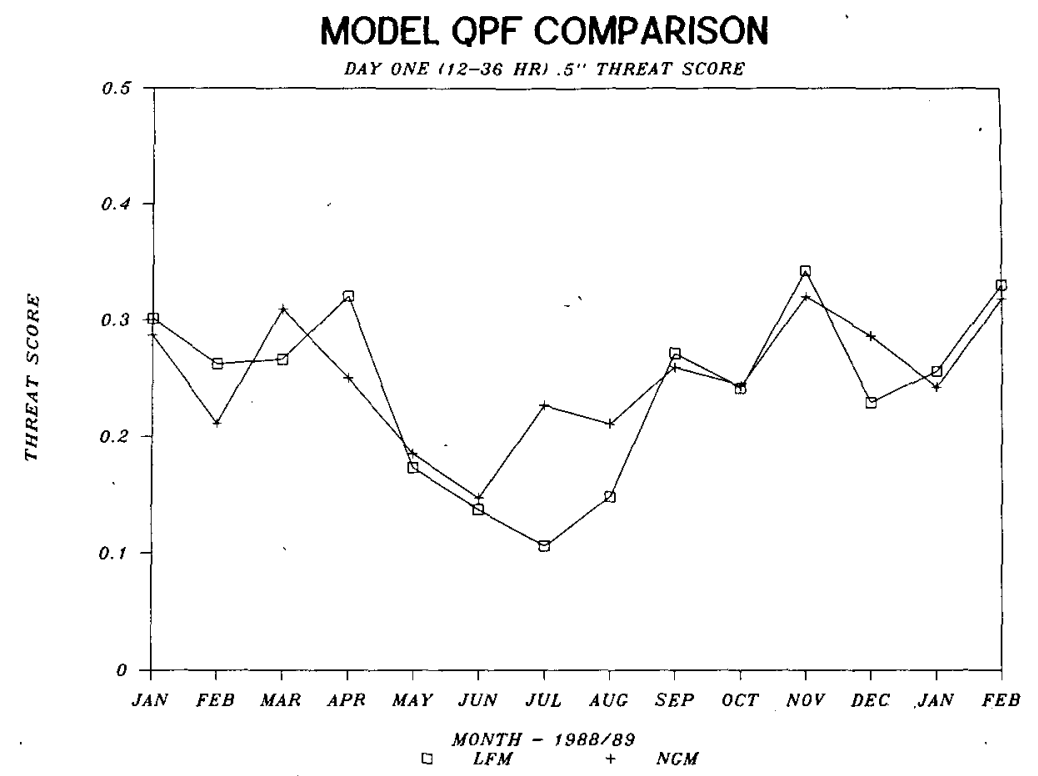

FIG. 5. Threat scores for LFM and NGM forecasts of $\geqslant 0.50$ in. precipitation for the 24-h period (12-36 h of the model forecasts) valid at 1200 UTC for January 1988February 1989 . Verification is a $31.5-\mathrm{km}$ resolution analysis of precipitation observations from an extensive network over the United States east of $107^{\circ} \mathrm{W}$.

itation. During the cold season, the threat scores are almost the same.

The LFM's overprediction of precipitation in the cooler part of the year is partially the result of an error in which the postprocessed grid-scale precipitation is twice the amount actually generated internally by the model's physics. Discovered in 1981 (W. Collins, personal communication), this error was not corrected for several reasons. One important reason was that LFM precipitation forecasts are disseminated on facsimile circuits only as a backup during the rare occasions when NGM forecasts are not available. Therefore, forecasters receiving forecast products this way would not have extensive experience with the new behavior of the LFM precipitation forecasts. Second, removing the factor-of- 2 error led to a general degradation in threat scores. This somewhat surprising result was due in part to the fact that fine tuning of the LFM (such as adjusting its precipitation bias to an optimal level) took place while the postprocessing error was in place (D. Deaven, personal communication).

In addition to the verification of precipitation forecasts against analyses, NMC routinely calculates biases and threat scores directly from observations at 60 stations spread evenly across the 48 contiguous states to verify the $0.01 \mathrm{in}$. threshold (i.e., the rain/no rain threshold). Threat scores are typically higher during winter than summer, implying a decrease in skill during the convective season. The 0000 UTC model runs predict more precipitation than the 1200 UTC runs, with the difference in bias between the two runs greatest during the summer and smallest during the winter.
Despite having an overforecast problem during the cool season, the LFM predictions of precipitation can be more accurate than those of the NGM in certain synoptic regimes. Thirty-two 24 -h periods during November 1988-January 1989 were subjectively classified by synoptic pattern to see whether one model was superior to the other for different synoptic regimes. A few general conclusions could be drawn based on threat scores (F. Brody, personal communication). When precipitation was associated with an existing or closing off $500-\mathrm{mb}$ low or by a negatively tilting $500-\mathrm{mb}$ trough, the LFM's prediction of heavy precipitation along both the warm and cold fronts was usually superior to that of the NGM. The NGM, however, often was quite accurate in predicting a band of heavy precipitation along and ahead of the surface occlusion or triple point. The LFM prediction of precipitation amounts was usually worse than the NGM for a positively tilting 500-mb trough. In these cases, the LFM overforecast the amount of precipitation, especially north of the surface low and associated warm front.

Another precipitation-related problem in the LFM is the generation of intense vorticity maxima at 500 mb. Usually, the model forecasts these features in conjunction with heavy precipitation amounts and intense vertical velocities. These forecast fields are distinguished by their bull's-eye appearance, and the mean-sea-level pressure patterns can also be seriously distorted. In these situations, the model releases too much latent heat, which sets up a strong three-dimensional flow with low-level convergence and upper-level divergence. This CISK-like process (conditional instability of the 
second kind) intensifies the cyclonic vorticity at the levels of convergence and supplies moisture and, therefore, additional latent heat that sustain or strengthen the system. Sometimes, however, the heavy precipitation amounts generated by the model can be a clue to a synoptic pattern's rainfall potential.

\section{d. Summary of LFM performance}

The LFM is a valuable forecast tool used by forecasters to get a first look at weather systems during each new 12-h production cycle. Also, the LFM has been used operationally longer than the other NMC models and has not been modified recently. The resulting extensive experience with the model's strengths and weaknesses enables forecasters to adjust the model's prognoses. Some of these systematic characteristics are summarized below.

\section{Strengths:}

1) The LFM's lifted indices often depict low-level boundaries (such as arctic fronts) better than the 1000500 -mb thickness or mean-sea-level pressure forecasts of the LFM, NGM, and AVN/MRF.

2) The LFM has less of a cold bias over the Rocky Mountains and less of a warm bias over the eastern United States in the $850-500-\mathrm{mb}$ thickness than the NGM.

3) The LFM is often better than the NGM at forecasting heavy precipitation amounts in situations with a closed upper-level low or negatively tilting trough.

\section{Weaknesses:}

1) Cyclones are overdeveloped when moving out of the Rockies.

2) Nevada cyclogenesis is often not predicted.

3 ) Intensity of oceanic storms is often underestimated, and these storms are predicted to move too rapidly.

4) The intensity of anticyclones is underforecast.

5) Anticyclones are shifted eastward too quickly.

6) Gulf inflow is often developed prematurely.

7) Summer convective precipitation events are underforecast.

8) The amount of precipitation in cool-season nonconvective events is overpredicted.

9) The 0000 UTC model run produces more precipitation than the 1200 UTC run.

10) The rain shadow east of major mountain ranges is poorly predicted.

\section{Performance of the NGM}

The National Meteorological Center introduced the RAFS, including the NGM as the forecast model component, as an operational forecast system in March
1985. A description of the system is presented elsewhere in this issue (Hoke et al. 1989). The behavior of the NGM in predicting temperature, atmospheric processes near the earth's surface (especially the diurnal cycle), cyclones, anticyclones, and precipitation is discussed in this section.

\section{a. Temperature prediction}

The NGM has both strengths and weaknesses in its ability to predict temperature. One of its strengths is a realistic diurnal cycle in temperature, to be discussed in more detail in section 3b. By contrast, the LFM has a much less pronounced cycle. This is one reason that the 1000-500-mb NGM thickness forecasts show more diurnal change than the LFM.

A second strength of the NGM with respect to the LFM is its generally better prediction of various temperature (and height) fields at most levels and time ranges. This was shown in Table 1 , which gives the mean and standard deviation errors of temperature (and height) by pressure level and forecast hour over North American land points during the period MarchMay 1988. The results for standard deviation error are displayed graphically in Fig. 6b for December 1987February 1988. This error initially is small in the NGM, but increases rapidly during the first $12 \mathrm{~h}$ of the forecast. Subsequent growth is much slower, however, with an error near the tropopause of about $2.4^{\circ} \mathrm{C}$ at $48 \mathrm{~h}$. Error growth in low levels is especially rapid in the NGM, possibly reflecting both a systematic temperature forecast error that shows up early over the Rocky Mountains and the inability of the analysis to capture the observed diurnal cycle. The initial error is large in the LFM (Fig. 6a), especially near the tropopause where the error increases to over $3.2^{\circ} \mathrm{C}$ by $48 \mathrm{~h}$.

A major problem in the NGM is the tendency to forecast temperatures too cold in the troposphere. The error has two components: a general cold bias throughout the troposphere and a strong cold bias over the mountains. In the first component, the cooling effect of longwave radiation is not sufficiently balanced by other processes, such as solar and latent heating, so that the entire troposphere cools too rapidly during the forecast. This cold bias was corrected in October 1987 with the implementation of a hemispheric temperature adjustment (Phillips 1987). Now the mean hemispheric potential temperature for each of the 16 model layers is restored every hour to its initial value.

The adjustment procedure does not, however, remove the second component of the temperature error, the cold bias over the Rocky Mountains. As a result of the hemispheric temperature adjustment, the mountainous western United States is not as cold, but the East is too warm. Figure 1 shows the mean 850500-mb thickness error for March-May 1988. The negative error over the Rocky Mountains reflects the model's cold bias, and the positive error east of the 

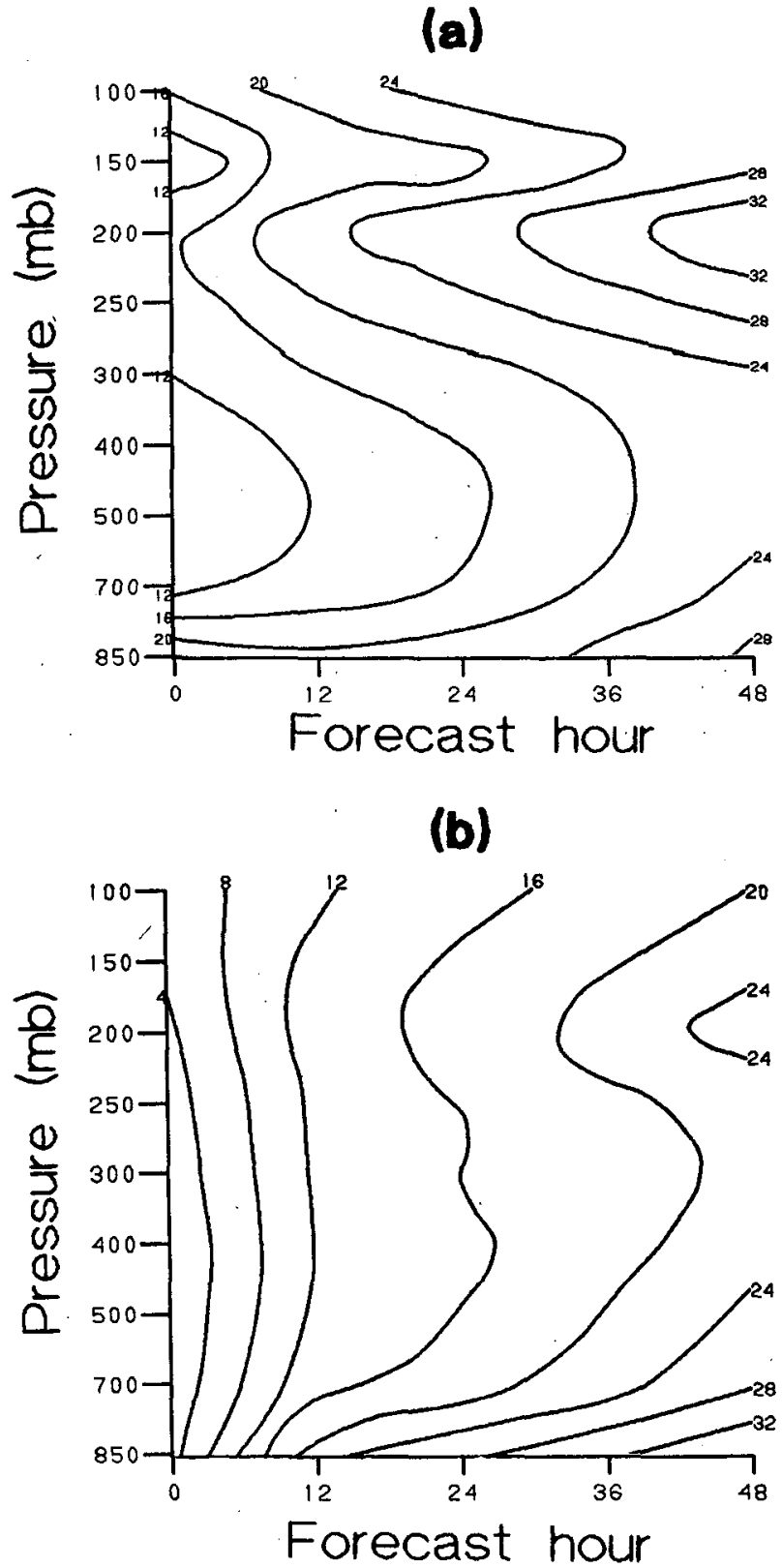

FIG. 6. Standard deviation of the temperature error (in tenths ${ }^{\circ} \mathrm{C}$ ) at mandatory pressure levels for (a) the LFM, and (b) the NGM, as a function of forecast hour over North American land points. Verification for each forecast model was its own analysis for the period December 1987-February 1988 (Keyser et al. 1988a).

Rockies indicates the warm bias resulting from the hourly hemispheric temperature adjustment. This systematic error pattern is typical of other months as well. Much of the tropospheric temperature error is present at $12 \mathrm{~h}$ into the forecast, indicating a rapid adjustment of the forecast model to a climatology significantly different from that of the analysis (Phillips 1988).

\section{b. The boundary layer and the diurnal cycle}

The behavior of the NGM near the earth's surface is determined in large part by the surface energy budget; the exchange of heat, moisture, and momentum at the earth's surface; and the boundary-layer mixing formulation. As described in Tuccillo and Phillips (1986) and Hoke et al. (1989), a surface energy budget is used to determine the surface (also called skin) temperature over land. The processes in this budget are shortwave radiation from the sun, longwave radiation, exchange of heat between the earth's surface and the bottom model layer, evaporation and condensation at the ground, and the transfer of heat with the subsoil. The surface temperature changes when these processes are not in balance. Over the oceans the surface temperature is defined by the sea surface temperature analysis and is held constant during the forecast. The surface temperature directly affects the exchange of heat, moisture, and momentum between the earth's surface and the bottom layer of the model atmosphere.

Surface and ground features strongly influence the behavior of the model in the lower troposphere. Features of major importance are snow cover, ice cover, soil moisture, and subsoil temperature. Because of the dominance of the sun in the evolution of all these processes, the presence of cloud cover is a strong modulating effect.

Near the earth's surface, if there is sufficient solar heating or strong enough winds, a mixing process (Phillips 1986) produces a boundary layer of constant potential temperature and specific humidity. Turbulence due to buoyancy and wind shear also vertically mixes the winds in the boundary layer and above.

Figure 7 illustrates the net effect of all these boundary-layer-related processes at Midland, Texas during a 48-h NGM forecast starting at 1200 UTC 10 June 1988. The maximum in solar (shortwave) radiation occurs when the sun is highest in the sky, but the surface temperature maximum lags the radiation maximum by several hours. The response in the bottom-layer temperature is even more delayed, and of lesser amplitude than that of the surface temperature. In the second model layer, the diurnal cycle is still evident, but less so, because the effect of the sun decreases away from the ground. At night, the solar radiation drops to zero and the sensible heat and latent heat (moisture) flux at the surface become very small. Therefore, by dawn, the surface temperature is determined by the balance of the cooling effect of the longwave radiation and the warming from the subsoil. Figure 7 also shows that increasing cloud cover in the second day of the forecast reduces the diurnal cycle in the shortwave radiation reaching the earth's surface and, therefore, the response in surface temperature is less.

A pronounced diurnal cycle in the NGM forecasts of low-level wind speed was reported by Phillips 

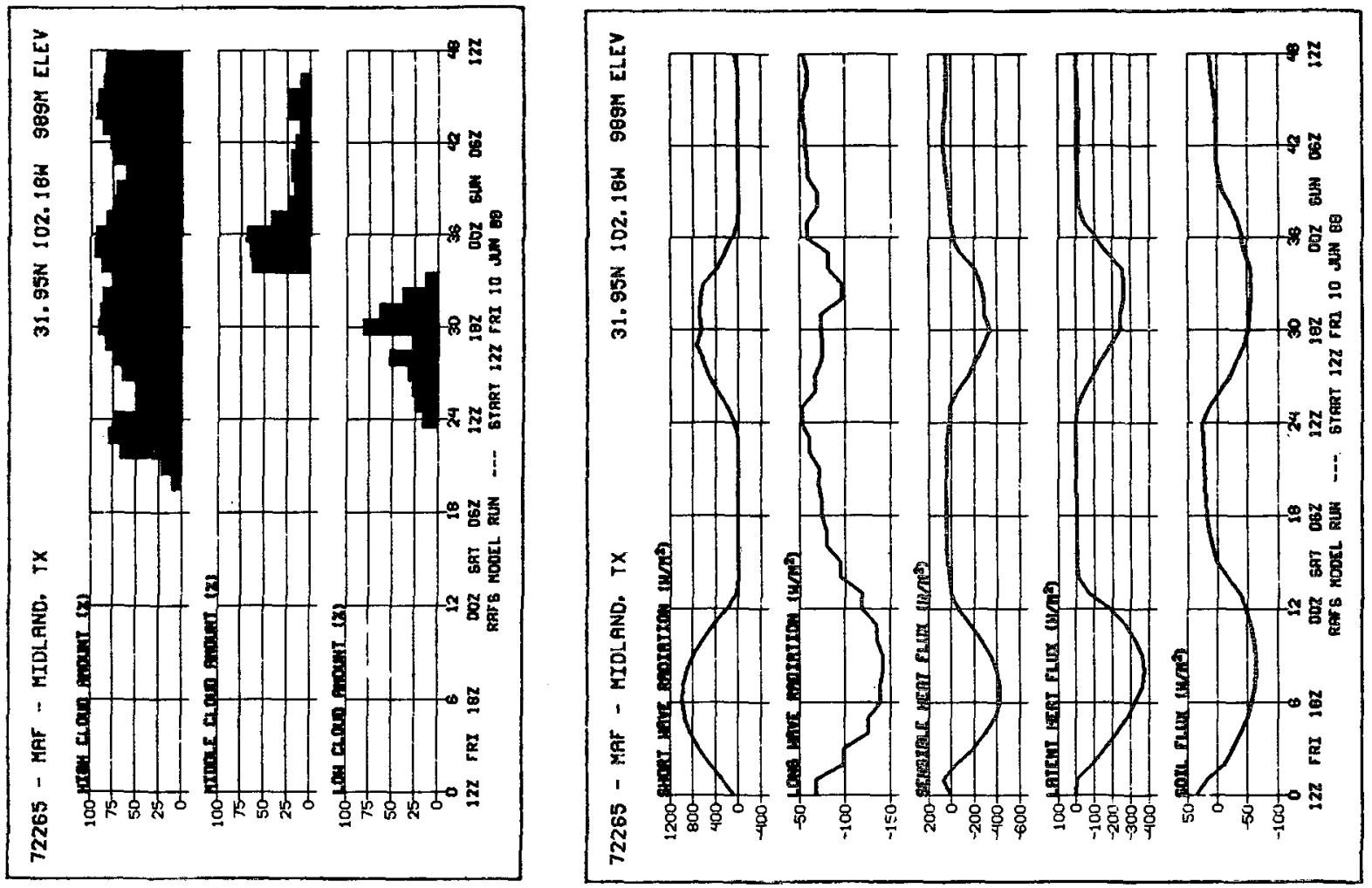

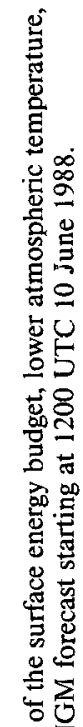

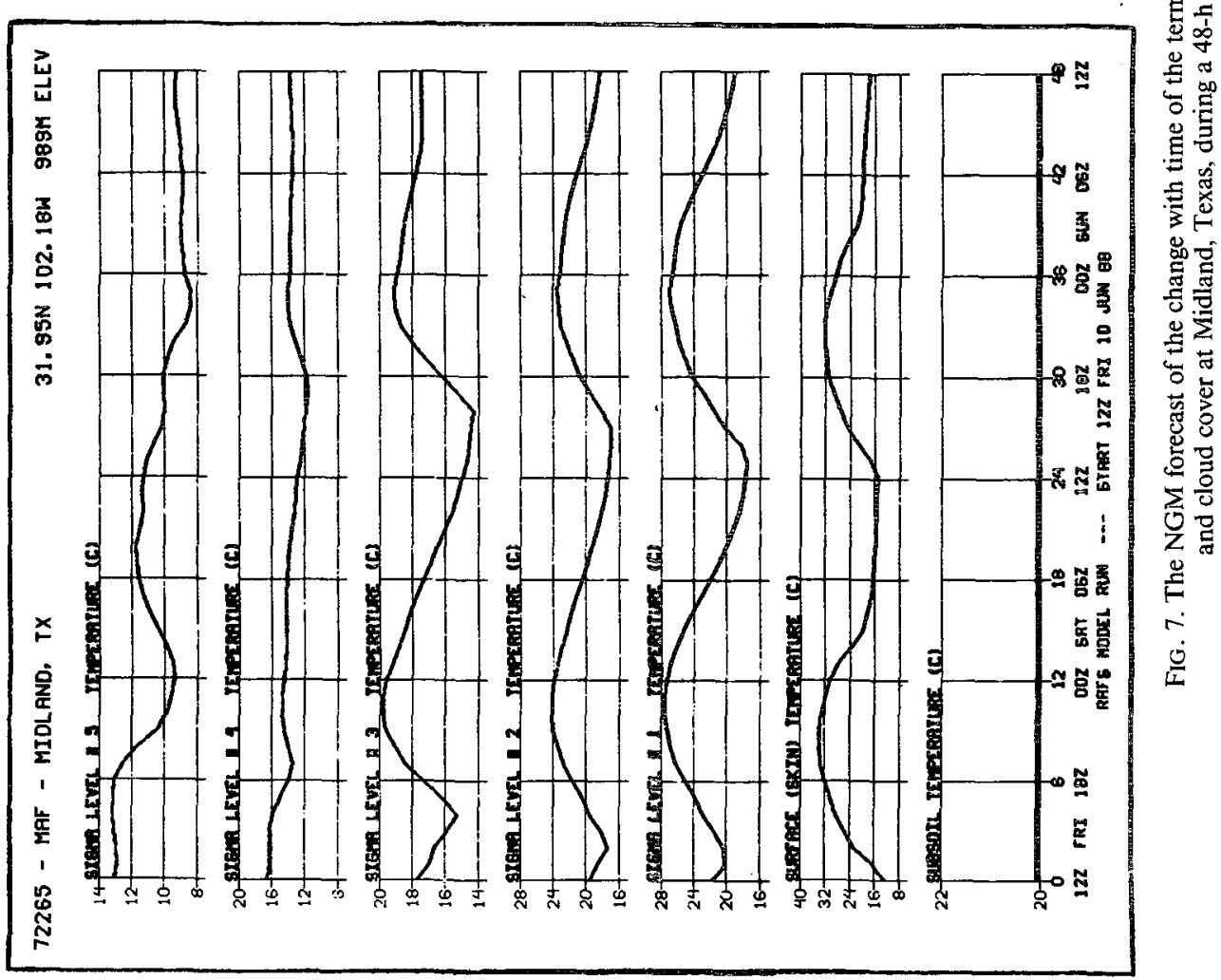




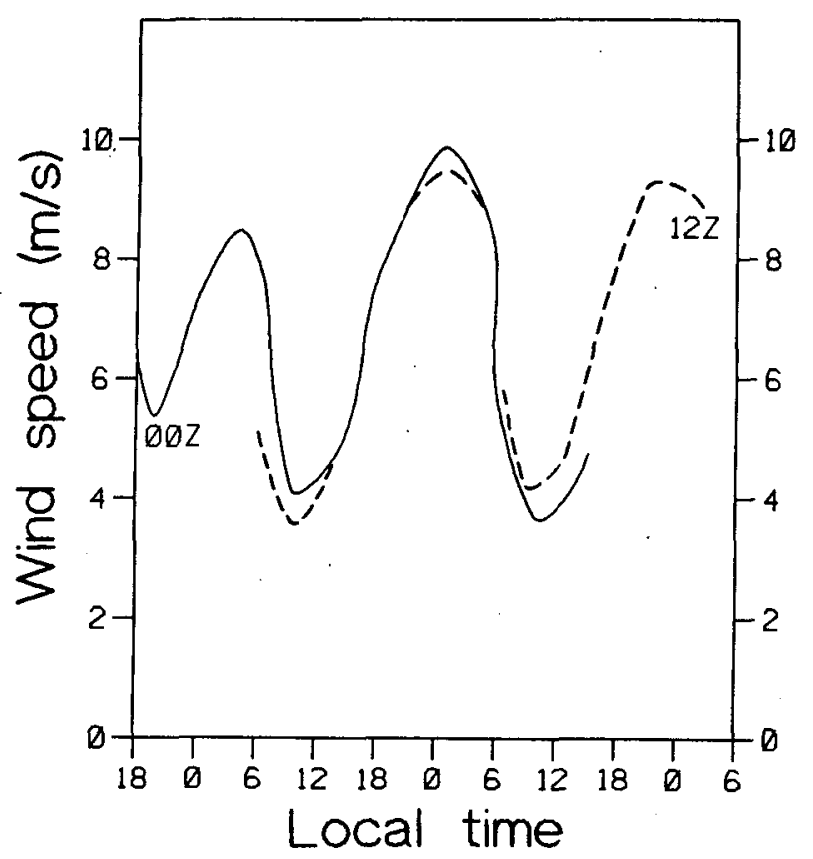

FIG. 8. The diurnal variation of the wind speed in the bottom layer of the NGM for 22 forecasts from 0000 UTC (solid curve), and 22 forecasts from 1200 UTC (dashed curve) from 9 June to 30 June 1986. The forecasts were averaged over four locations in eastern Colorado (from Phillips 1988). The midpoint of the bottom model layer is about $150 \mathrm{~m}$ above ground. Mountain daylight savings time (MDST) is the local time ( 1800 MDST corresponds to 0000 UTC).

(1988). ${ }^{2}$ Figure 8 shows the average forecast speed from four locations in eastern Colorado east of the Front Range. The wind speed in the bottom layer of the model varied about $6 \mathrm{~m} \mathrm{~s}^{-1}$ between day and night with a maximum at night. Such behavior is typical of the nocturnal jet, but not the surface wind.

The diurnal cycle in the winds over land in the NGM is the result of two processes. First, the surface drag coefficient is large during the day as solar heating decreases low-level stability, so that the bottom layer of the model is more strongly influenced by the ground. This drag effect by itself tends to reduce the low-level wind. Secondly, vertical turbulent mixing of the air between layers increases in the NGM as the Richardson number drops during the day, once again as the result of solar heating. Because winds normally increase with height, this process by itself will increase low-level winds. Unfortunately the first effect currently dominates the second in the NGM, yielding a minimum in the wind speed during the day in the bottom layer of the model. The bottom layer is a relatively thick $35-$ mb slab, with the wind forecast at the middle of the layer at a height of about $150 \mathrm{~m}$ above the ground. To produce a wind forecast more representative of anemometer level, the NGM needs greater vertical reso-

\footnotetext{
${ }^{2}$ The study of the diurnal cycle was by W. Collins (NMC).
}

lution near the surface of the earth and a more realistic method for modeling the downward transport of momentum during the day.

\section{c. A scale problem in forecasting the sea breeze}

As shown above, the NGM's modeling of the atmosphere near the earth's surface includes many of the processes that exist in nature. Unfortunately, some of these processes occur in nature at a much smaller horizontal scale than can be resolved by the $85-\mathrm{km}$ spacing of NGM grid points. As reported by Petersen (1988), one symptom of this problem is the development of a sea breeze several hundred kilometers further inland than occurs in nature (Fig. 9). Note in the figure the wide region of convergence inland extending from central Louisiana along the East Coast all the way to New England, with values exceeding $-3\left(10^{-5}\right) \mathrm{s}^{-1}$ in Florida and $-2\left(10^{-5}\right) \mathrm{s}^{-1}$ in eastern North Carolina and Virginia. Strong divergence occurs offshore. As a result of the enhanced low-level convergence, the NGM sometimes overforecasts the extent of precipitation. Similarly, the model can develop lake breezes around the Great Lakes that extend much farther inland than in nature, as indicated by the divergence over Lakes Michigan and Huron and the convergence over Wisconsin. Unrealistic monsoonal-scale upslope flow and heavy precipitation are often predicted over Central America for a similar reason.

\section{d. Impact of snow and ice cover on the NGM}

The behavior of the model is greatly affected by the presence of ice at a point over water or snow at a point over land (Petersen and Hoke 1989). Over both ice and snow the albedo is increased, so the net incoming solar radiation is reduced. More importantly, over ice the exchange of heat and moisture between the ocean (and lake) surfaces and the lowest atmospheric layer of the model is greatly reduced. Because the ice-snow analysis used by the NGM has coarse resolution, snow cover in the vicinity of the Great Lakes can mistakenly be interpreted as ice cover, so that the lakes appear to be frozen to the model. Consequently, some or all of the 35 grid points over the lakes are no longer significant sources of heat and moisture in the model. The usefulness of the model in forecasting lake-effect events, therefore, greatly decreases as the snow cover around the lakes increases in early winter (T. Niziol, personal communication ).

Another effect of snow cover in the NGM is to limit surface temperature to be no more than $0^{\circ} \mathrm{C}$, even when there is strong solar heating over thin snow covers. Such a constraint is necessary because a snow depth analysis is not available, so that the model cannot melt snow during the forecast. Another problem is that the snow cover analysis available to the NGM is updated 


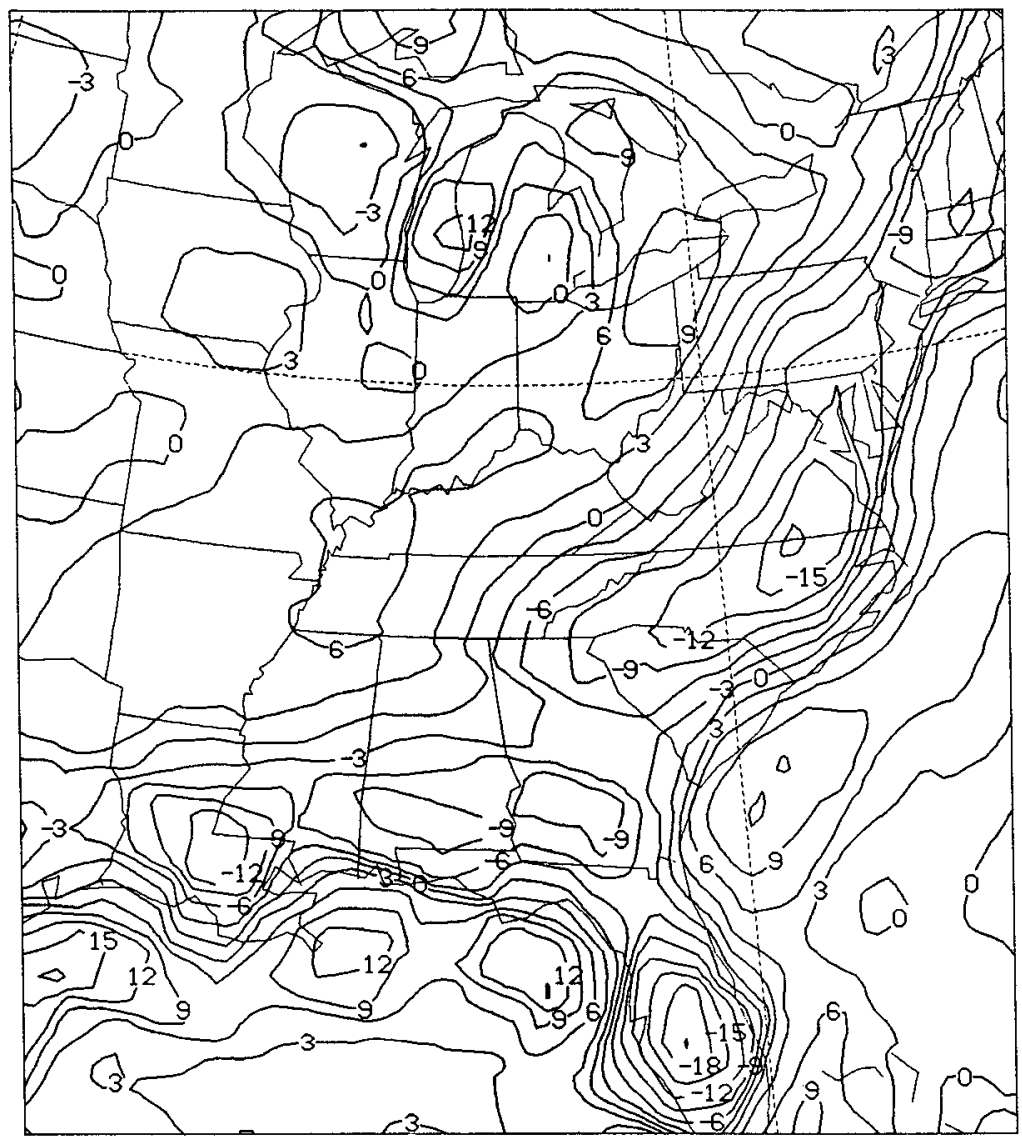

FIG. 9. Average divergence at $0000 \mathrm{UTC}$ in the bottom layer for all $12-\mathrm{h}$ NGM forecasts from 1200 UTC during the period 1-30 June 1988. Negative values indicate convergence. Contour interval is $3 \times 10^{-6} \mathrm{~s}^{-1}$.

only once a week, normally on Monday. Significant changes in the snow cover during the course of a week from melting or additional snowfall will not be reflected in the NGM. The existence in the model of snow at a point when it should be snow free has been shown to reduce bottom-layer air temperature in some cases by over $6^{\circ} \mathrm{C}$. Therefore, when a forecaster is using the NGM to determine whether to favor snow or rain, the model's deficiencies in handling snow cover should be considered.

\section{e. Performance in predicting cyclones and anticyclones}

The LFM and NGM forecasts of surface lows were studied by Phillips for the eastern two-thirds of North America from November 1984-January 1985, as reported by Hoke et al. (1985). The LFM was a little too fast in moving the surface lows, with a mean vector position error of $105 \mathrm{~km}$ to the east-southeast at $48 \mathrm{~h}$. The NGM was too slow by $60 \mathrm{~km}$ to the west. The mean distance error for the LFM was $411 \mathrm{~km}$ and for the NGM was $322 \mathrm{~km}$. Errors at $24 \mathrm{~h}$ were about onehalf as large for both models.
Grumm and Siebers (1989) examined the ability of the NGM to forecast the centers of surface cyclones for the period 13 November 1988-31 January 1989, in a manner similar to that of Silberberg and Bosart (1982) for the LFM. The NGM forecasts of the position and central pressure of surface lows every $6 \mathrm{~h}$ from 6 to $48 \mathrm{~h}$ were compared to those given by the corresponding NGM initialized analysis. A low was required to have one closed isobar (when analyzed at 4-mb intervals) for inclusion in the study. Four regions were studied (Fig. 10). The biggest position errors were found in the southeast quadrant, where the NGM generally forecast cyclones west-northwest of the observed positions. The magnitude of the mean vector position error grew during the forecast from about $90 \mathrm{~km}$ at 24 $\mathrm{h}$ to $310 \mathrm{~km}$ at $48 \mathrm{~h}$ for this quadrant. Figure 11 shows a scatter diagram of the error in 48-h cyclone position. The second largest mean vector position error was found in the southwest quadrant, where cyclones were usually forecast too far to the north of the observed position. This error increased from about $160 \mathrm{~km}$ at $24 \mathrm{~h}$ to about $200 \mathrm{~km}$ at $48 \mathrm{~h}$. The northeast and northwest quadrants, which had $80 \%$ of the 661 cases 


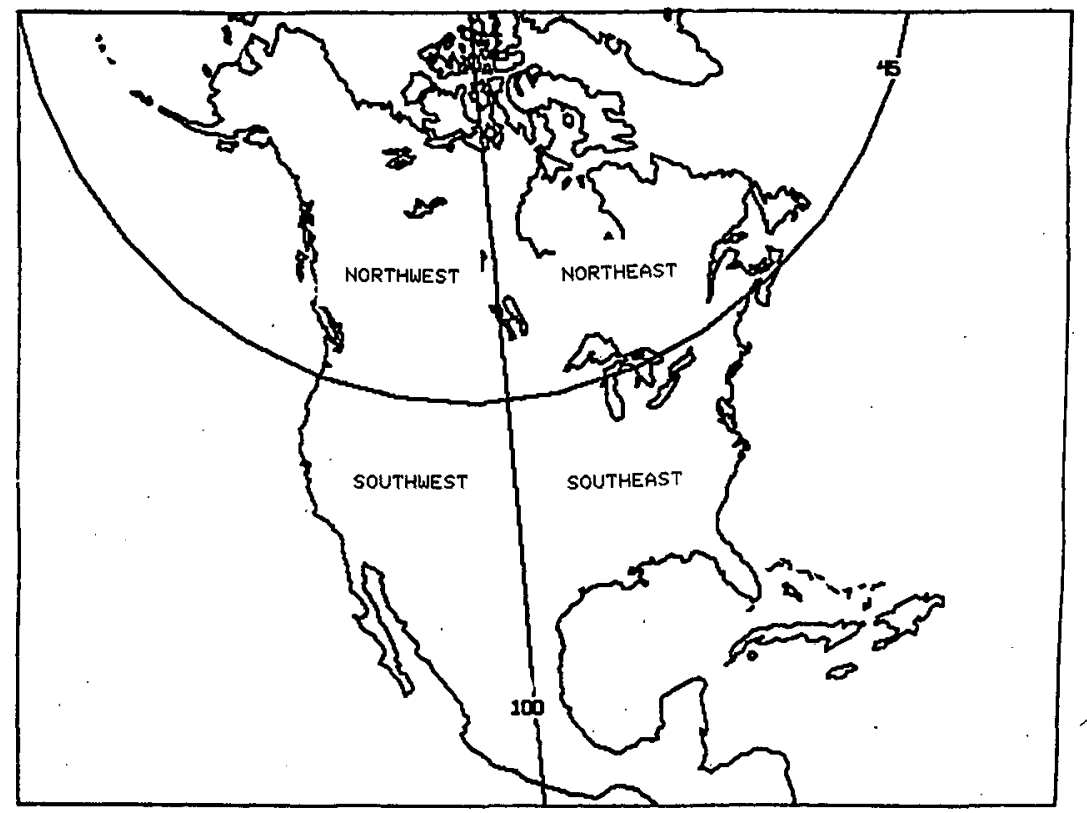

FIG. 10. The four geographical areas used by Grumm and Siebers (1989) in studying the NGM's ability to forecast the depth and location of surface lows.

at $24 \mathrm{~h}$ and $84 \%$ of the 501 cases at $48 \mathrm{~h}$, showed a more random distribution with no easily recognizable directional bias and, therefore, much smaller mean

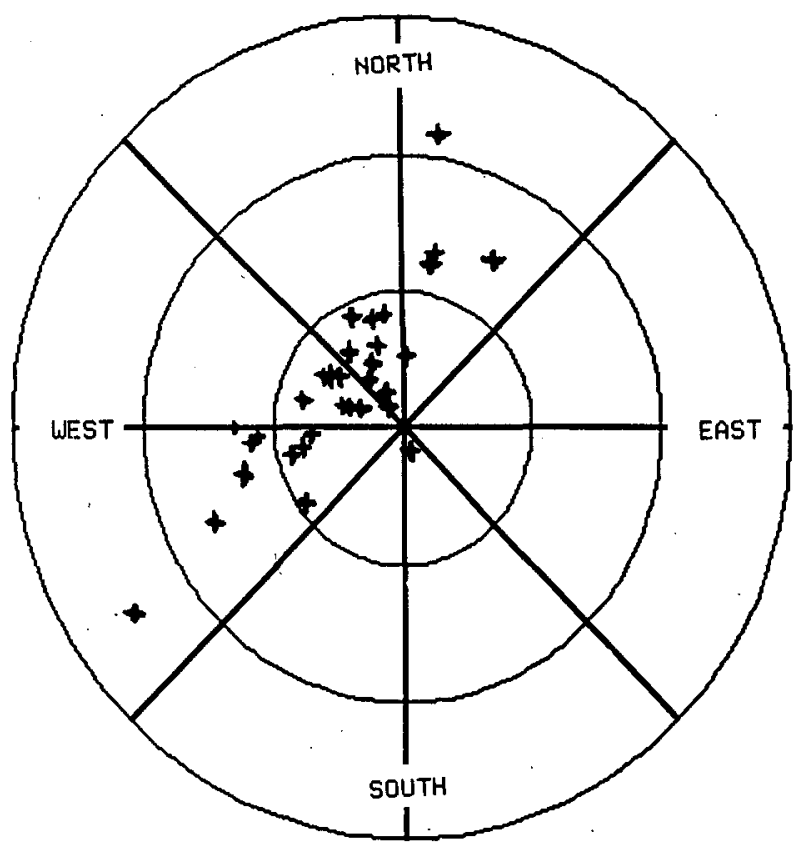

FIG. 11. Scatter diagram of the error in 48-h surface cyclone positions for NGM forecasts from 13 November 1988-31 January 1989 for the southeast quadrant of Fig. 10. The center of the circle is the observed position. Each plus symbol represents a surface cyclone. A position directly north of the center indicates that the forecast position was north of the observed position. The distance between concentric circles of position error is $500 \mathrm{~km}$. vector position errors. The mean vector position error over all cases in all four quadrants was only $54 \mathrm{~km}$ at $24 \mathrm{~h}$, and $55 \mathrm{~km}$ at $48 \mathrm{~h}$ to the northwest. Over all cases, the mean distance error was $256 \mathrm{~km}$ at $24 \mathrm{~h}$ and $417 \mathrm{~km}$ at $48 \mathrm{~h}$.

The geographical distribution of central pressure errors in surface cyclones for $12,24,36$, and $48 \mathrm{~h}$ was also determined by Grumm and Siebers (1989) for the period 13 November 1988-31 January 1989 . The difference between the forecast central pressure at mean sea level and the central pressure of the initialized analysis was calculated and placed in a $5^{\circ}$ lat $\times 5^{\circ}$ long box based on the observed position of the low. Figure 12 shows the geographical distribution of the mean error in cyclone central pressure at $48 \mathrm{~h}$. In the mean, the NGM underdeveloped lows over the Atlantic Ocean, especially off the New England coast, but predicted lows to be too deep over the North American continent at all time periods.

Consistent with these findings is that the NGM often overdeepens lows coming out of the Rocky Mountains. One consequence of this problem was apparent during the arctic outbreak of late January and early February 1989 that was associated with the highest mean-sealevel pressure ever recorded in North America. Figure 13 shows the NGM 48-h mean-sea-level pressure and the 1000-500-mb thickness forecast valid at 0000 UTC 3 February 1989, with Fig. 3b providing the verifying analysis. The NGM predicted that a surface low over the Rockies would move eastward into Kansas and strongly deepen, whereas the low actually remained over the mountains and did not intensify. The spurious cyclogenesis in the NGM and associated warm advec- 


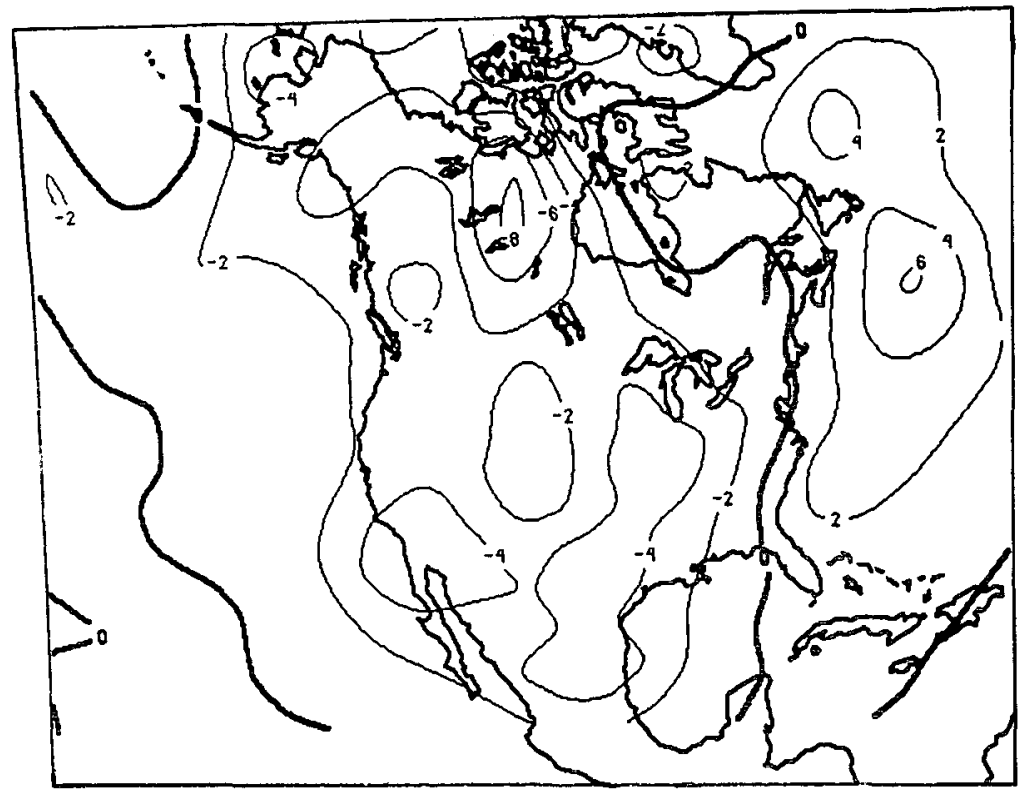

FIG. 12. The 48-h errors in mean-sea-level pressure at the center of cyclones for the period 13 November 1988-31 January 1989. Error is defined as the central pressure of the cyclone forecast by the NGM minus the central pressure of the observed cyclone in the initialized analysis. Values are plotted at the location of each observed cyclone. Contour interval is $2 \mathrm{mb}$.

tion ahead of the low prevented the strong southward thrust of cold air through the Great Plains. Large errors in the forecast temperatures resulted. Evaluation of the case at NMC indicates that the problem was due in part to the inability of the analysis to capture the shallow cold air, as well as the specification of terrain in the NGM.

The ability of the NGM to forecast explosive cyclogenesis was assessed by Sanders (1987) by comparing $0-48 \mathrm{~h}$ forecasts to manual analyses covering the eastern North Pacific, North America, and western Atlantic during the period 1 September 1986-30 April 1987. He found that the NGM's success in detection was greater over the high-resolution portion of the model's domain than outside this area. The NGM was much more likely to detect bomb development in the Atlantic than in the Pacific Ocean. Forecast skill decreased with length of forecast; i.e., a 48-h forecast was less likely to detect explosive cyclogenesis than a 12-h forecast. Sanders concluded that for the North Atlantic and North America the NGM performance in detection was a distinct improvement over that of the LFM during 1981-84 (Sanders 1986). It is important to note that on 25 February 1987 the high-resolution grid-C of the NGM was expanded significantly westward in the Pacific and eastward in the Atlantic. Tests showed dramatic improvement in the NGM's ability to forecast the explosive cyclogenesis for many cases originally outside the high-resolution domain (Hoke 1987).

The usefulness of the NGM in predicting explosive cyclogenesis is demonstrated by the technique devel- oped by Sanders and Auciello (1989). They devised the following checklist, which applies only to the Atlantic Ocean north of $40^{\circ} \mathrm{N}$ and west of $60^{\circ} \mathrm{W}$, in which explosive cyclogenesis is predicted if at least four of the six checklist criteria are met:

1) The strength of the $500-\mathrm{mb}$ absolute vorticity maximum is $\geqslant 1.7 \times 10^{-4} \mathrm{~s}^{-1}$.

2) The vorticity maximum stays the same or strengthens during the NGM forecast.

3) The vorticity maximum is forecast to move faster than $30 \mathrm{kt}\left(15.4 \mathrm{~m} \mathrm{~s}^{-1}\right)$.

4) The vorticity maximum crosses the Atlantic coast between $32^{\circ}$ and $45^{\circ} \mathrm{N}$.

5) A jet streak $\geqslant 110 \mathrm{kt}\left(57 \mathrm{~m} \mathrm{~s}^{-1}\right)$ exists at 250 or $300 \mathrm{mb}$ just south of the initial vorticity maximum.

6) The NGM forecasts a surface low of $990 \mathrm{mb}$ or deeper over the Atlantic Ocean north of $38^{\circ} \mathrm{N}$ and west of $55^{\circ} \mathrm{W}$.

Forecasters at the Boston Weather Service Forecast Office operationally used the checklist from October 1988-March 1989 (E. Auciello, personal communication). The method predicted 20 bombs, correctly forecasting 13 of the 16 that were observed. Thus, the technique failed to forecast only three of the observed bombs and forecast seven storms that did not occur. The threat score [given by Eq. (1) and identical to the critical success index of Donaldson et al. 1975] for the season was 0.56 . More importantly, the probability of detection (the number of bombs correctly forecast di- 


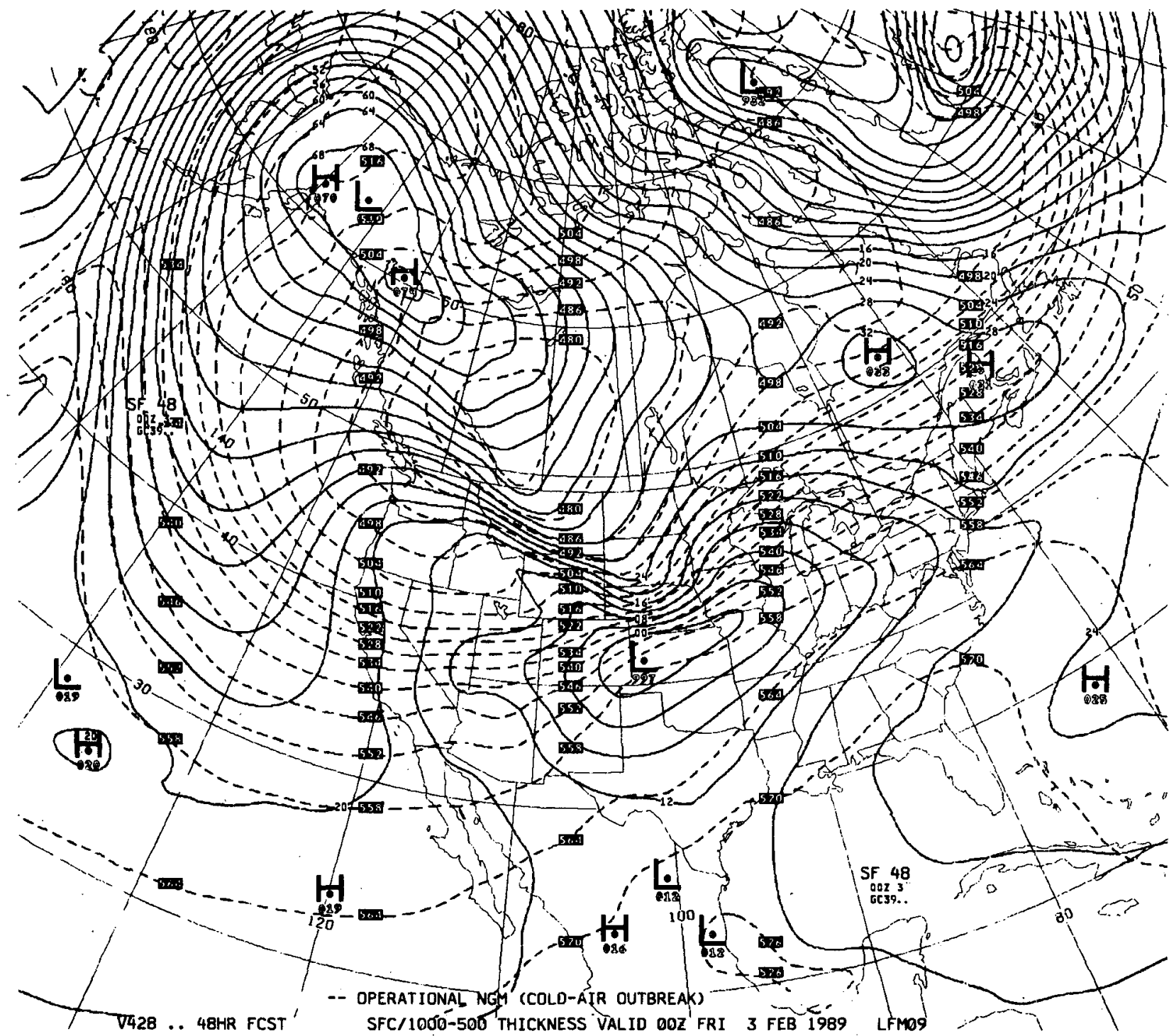

FIG. 13. Mean-sea-level pressure (4-mb contour interval) and 1000-500-mb thickness (6-dm contour interval) at 0000 UTC 3 February 1989 for the operational 48-h NGM forecast. The verifying analysis is given by Fig. 3 b.

vided by the number of bombs observed) was 0.81 , which was higher than the 0.44 found by Sanders (1987) for the NGM using the 12-h forecast of meansea-level pressure to predict development.

The ability of the NGM to predict anticyclones is the subject of an ongoing study by Grumm and Siebers for the period 13 November 1988-31 January 1989. The NGM forecasts over North America were partitioned into four regions (Fig. .10). Then 12-, 24-, 36and 48 -h forecasts of anticyclones were compared to the observed anticyclones in the initialized analysis. The magnitude of the mean vector position error was $<80 \mathrm{~km}$ for all quadrants at all forecast times, with the mean direction error highly dependent on quadrant. Over all cases in all four regions, the mean distance errors for anticyclones at 24 and $48 \mathrm{~h}$ were 261 and $334 \mathrm{~km}$, respectively. The latter is significantly less than the 510-km error mentioned above for the LFM study by Grumm and Gyakum during the winter of $1981 / 82$.

As part of the same study for the period 13 November 1988-31 January 1989, Grumm and Siebers found that the NGM slightly overforecast central pressures of surface anticyclones over the western contiguous United States, with a mean error exceeding $2 \mathrm{mb}$ centered over Montana at $48 \mathrm{~h}$ (Fig. 14). A small negative pressure error extended from the Tennessee Valley northward into the Great Lakes region to Hudson Bay. The pattern is reminiscent to that of the $850-500-\mathrm{mb}$ thickness error for the NGM, shown in Fig. 1b, where the NGM was too cold over the western United States.

Finally, cold-air damming in the lee of the Appalachian Mountains is indicated better by the mean-sealevel pressure and 1000-500-mb thickness forecasts of 


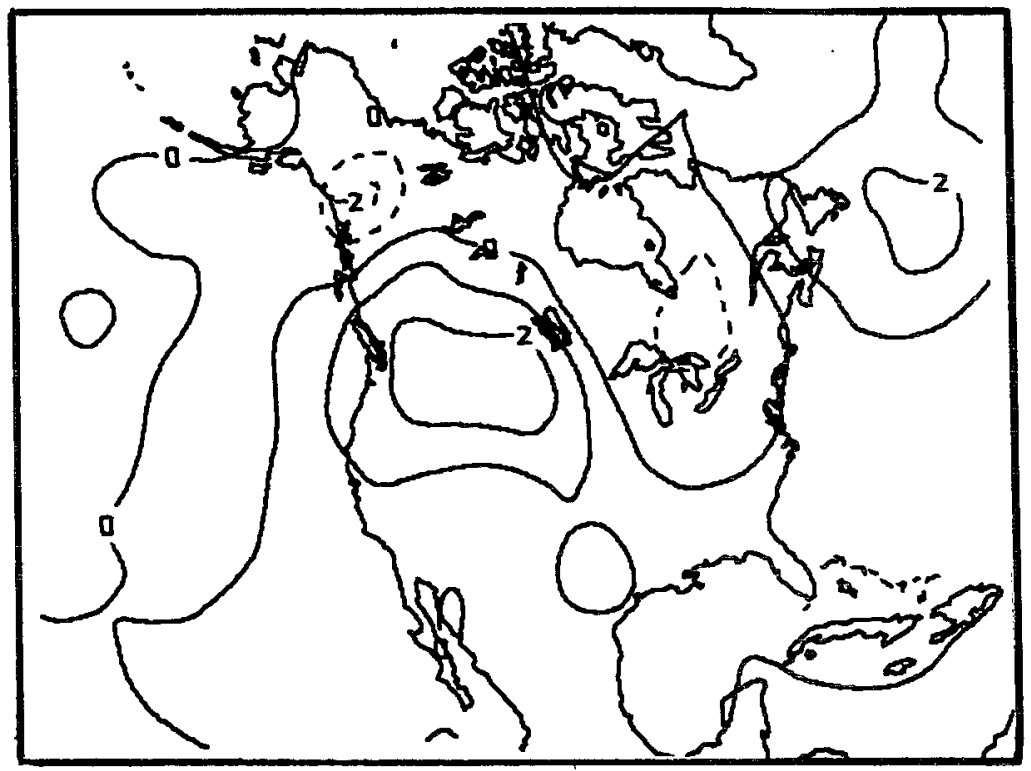

FIG. 14. The 48-h errors in mean-sea-level pressure at the centers of anticyclones for the period 13 November 1988-31 January 1989. Error is defined as the central pressure of the anticyclone forecast by the NGM minus the central pressure of the observed anticyclone in the initialized analysis. Values are plotted at the location of each observed anticyclone. Contour interval is $1 \mathrm{mb}$.

the NGM than the LFM. The NGM has much less of a tendency to erode the surface ridge than the LFM. Probable reasons for improved NGM performance are its higher horizontal and vertical resolution with respect to the height of the Appalachians and the width of the coastal plain to the east.

\section{f. Precipitation prediction}

The ability of the NGM to forecast precipitation is presented in terms of 1 ) the impact of changes made to the NGM during 1987, 2) general precipitation performance as a function of forecast time and precipitation amount, and 3) how well the NGM predicts precipitation in certain synoptic patterns and geographical regions.

\section{1) IMPACT OF 1987 CHANGES ON PRECIPITATION FORECASTS}

Changes were made to the NGM in 1987 to incorporate more realistic divergent circulations in the initial conditions, to eliminate the hemispheric cold bias in temperature forecasts, and to save computer time. These three modifications affected the model's precipitation forecasts.

In August 1987, the first change reduced the number of vertical modes in the nonlinear normal mode initialization from 8 to 2 (Carr et al. 1989). The purpose of the initialization is to remove nonmeteorological gravity waves from the forecast. With eight-mode ini- tialization, too much low-level convergence and upperlevel divergence were removed from the analysis. Therefore, the NGM was slow in generating precipitation, so that the model underforecast precipitation during the first $12 \mathrm{~h}$. Switching to two vertical modes reduced this spinup problem by increasing total precipitation in the first $12 \mathrm{~h}$ and reducing it in the following $36 \mathrm{~h}$. For a test period in May 1987, bias and threat scores [defined in Eq. (1)] for light to heavy amounts of precipitation generally improved over the United States east of the Rocky Mountains, which is the domain of the high-resolution precipitation analysis at NMC (Nierow 1985). Total precipitation dropped slightly, from $122 \%$ of the observed total to $119 \%$ of the observed total for the test period.

The hemispheric adjustment procedure mentioned in section 3a was implemented in October 1987. Because this method, in general, warmed the model troposphere by about $1^{\circ}-1.5^{\circ} \mathrm{C}$ at $48 \mathrm{~h}$, the tropospheric relative humidities dropped by about $10 \%$ from what they had been previously, so that less precipitation was predicted. The change reduced by $5 \%-10 \%$ the areal coverage for light, moderate, and heavy amounts of precipitation for a 25-case test for the first half of August 1987 (Phillips 1987). The overprediction of amounts of at least $0.01 \mathrm{in}$. (the rain/no rain threshold) was reduced. Unfortunately, the model was already underforecasting the areal extent of heavier precipitation ( $\geqslant 0.50 \mathrm{in}$.) during the cold season, so that the change worsened this problem.

The third change that modified the precipitation performance of the NGM was the implementation in 
December 1987 of a 15-min time step for the calculation of precipitation (Phillips et al. 1988). This switch to a longer time step in the precipitation calculations, along with an increase in the length of time steps used for other diabatic processes, reduced the running time of the NGM from about 36 to $20 \mathrm{~min}$. For a 13-case sample during the second half of November 1987, the longer precipitation time step led to a reduction in the number of points forecast to have precipitation. The areal coverage of precipitation amounts $\geqslant 0.01 \mathrm{in}$./day dropped by $3 \%$, for amounts $\geqslant 0.50$ in./day by $9 \%$, and for $\geqslant 1.00 \mathrm{in}$./ day by $8 \%$. Threat scores decreased as well.

An indication of the net effect of the various changes to the NGM in 1987 can be obtained by comparing precipitation scores for the period January-June 1987 (prior to the changes) with the period January-June 1988 (after the changes). Scores for amounts $\geqslant 0.50$ in./day are shown in Table 3.

As indicated by the bias scores in the table, the NGM was drier in 1988 in 4 out of 5 months than in 1987 for the 0.50 in. threshold. Because there can be significant interannual differences in actual precipitation, it is difficult to estimate the significance of these numbers. For that reason, comparison with the unaltered LFM is useful. The NGM-to-LFM change ratio relates the change in NGM performance between 1987 and 1988 to the change in LFM performance. This quantity is calculated by dividing the ratio of the NGM (bias or

TAB́LE 3. The impact of changes to the NGM in 1987 on the prediction of $\geqslant 0.50 \mathrm{in}$. of precipitation during the first $24-\mathrm{h}$ period. Scores are computed over the eastern United States, each of $107^{\circ} \mathrm{W}$, from a high-density raingage network (Nierow 1985). Bias and threat score are defined by Eq. (1). The NGM-to-LFM change ratio is calculated by dividing the ratio for the NGM score from 1988 to 1987 with the ratio of the LFM score for 1988 to 1987. Scores for April 1987 were not available.

\begin{tabular}{|c|c|c|c|c|c|}
\hline \multirow[b]{2}{*}{ Month } & \multicolumn{2}{|c|}{ NGM } & \multicolumn{2}{|c|}{ LFM } & \multirow{2}{*}{$\begin{array}{c}\text { NGM/LFN } \\
\text { change } \\
\text { ratio }\end{array}$} \\
\hline & $\begin{array}{c}1987 \\
\text { (Before) }\end{array}$ & $\begin{array}{c}1988 \\
\text { (After) }\end{array}$ & $\begin{array}{c}1987 \\
\text { (Before) }\end{array}$ & $\begin{array}{c}1988 \\
\text { (After) }\end{array}$ & \\
\hline \multicolumn{6}{|c|}{ Bias } \\
\hline Jan & 0.91 & 0.73 & 1.14 & 1.18 & 0.78 \\
\hline Feb & 0.78 & 0.48 & 0.95 & 0.98 & 0.60 \\
\hline Mar & 1.06 & 0.78 & 0.96 & 0.93 & 0.76 \\
\hline Apr & - & 0.96 & - & 0.86 & - \\
\hline May & 1.46 & 1.40 & 0.24 & 0.49 & 0.47 \\
\hline Jun & 1.13 & 1.94 & 0.08 & 0.16 & 0.86 \\
\hline \multicolumn{6}{|c|}{ Threat score } \\
\hline Jan & 0.47 & 0.34 & 0.41 & 0.35 & 0.85 \\
\hline Feb & 0.35 & 0.22 & 0.36 & 0.28 & 0.81 \\
\hline Mar & 0.36 & 0.33 & 0.32 & 0.30 & 0.98 \\
\hline Apr & - & 0.27 & - & 0.31 & - \\
\hline May & 0.22 & 0.18 & 0.08 & 0.16 & 0.41 \\
\hline Jun & 0.20 & 0.15 & 0.05 & 0.05 & 0.75 \\
\hline
\end{tabular}

threat) score for 1988 to 1987 by the ratio of the LFM for the same months. The NGM/LFM change ratio for bias in January is 0.78 , indicating that the NGM was $22 \%$ drier in 1988 than in 1987 , after taking into account the differences in actual precipitation (as indicated by the unchanged LFM) between the 2 yr. Note from the table that for all months the NGM/LFM change ratio for bias are less than unity. Thus, the NGM was drier in 1988 than in 1987. As indicated by the change ratio for threat score being less than 1 , the performance of the NGM in forecasting precipitation of $\geqslant 0.50$ in. also decreased.

A similar analysis was performed to determine how the changes impacted the prediction of measurable precipitation (i.e., amounts of $\geqslant 0.01$ in.). In general, the change ratios for bias (threat score) were less than (greater than) 1. Thus, the changes led to relatively drier, more accurate NGM forecasts of measurable precipitation. This was because the model was overpredicting the number of points with light precipitation before the changes were implemented.

\section{2) Precipitation Performance as a function OF TIME AND AMOUNT}

As mentioned above, the diurnal cycle in temperature is a prominent characteristic of the NGM. The diurnal cycle affects the amount of precipitation forecast by the model, especially during the warm half of the year. In a 14-case study for June 1986, Tuccillo and Phillips (1986) found that NGM forecasts originating at both 0000 and 1200 UTC preclicted significantly more precipitation for the 12 -h daytime period from 1200 UTC to 0000 UTC than for the nighttime period 0000 UTC to 1200 UTC. The diurnal differences in bias were especially true for areas of strong diurnal heating, such as Florida. This diurnal cycle in the precipitation, however, may be too strong for light amounts of precipitation. As indicated by Fig. 15, the bias for precipitation amounts $\geqslant 0.01 \mathrm{in}$. was $>2.0$ during the daytime in summer.

In addition to the diurnal cycle in NGM precipitation, there is a difference in forecast precipitation behavior depending on the time of day of the initial conditions. For the convective-season study of May 1987 (Carr et al. 1989), NGM forecasts originating at 1200 UTC produced $38 \%$ more total precipitation during the 48-h forecasts than those originating at 0000 UTC. The area studied was the eastern half of the contiguous United States. The reason for the difference in total precipitation between the two forecast cycles is not known. In contrast, more precipitation is forecast by the 0000 UTC LFM than the 1200 UTC run.

Recently, Jensenius ( 1989) studied LFM and NGM forecasts for the period 22 October 1987-31 March 1988. Figure 16a shows the average of both the 6-h observed and forecast precipitation for 230 stations during the 48 -h forecasts. Both models were slow to 


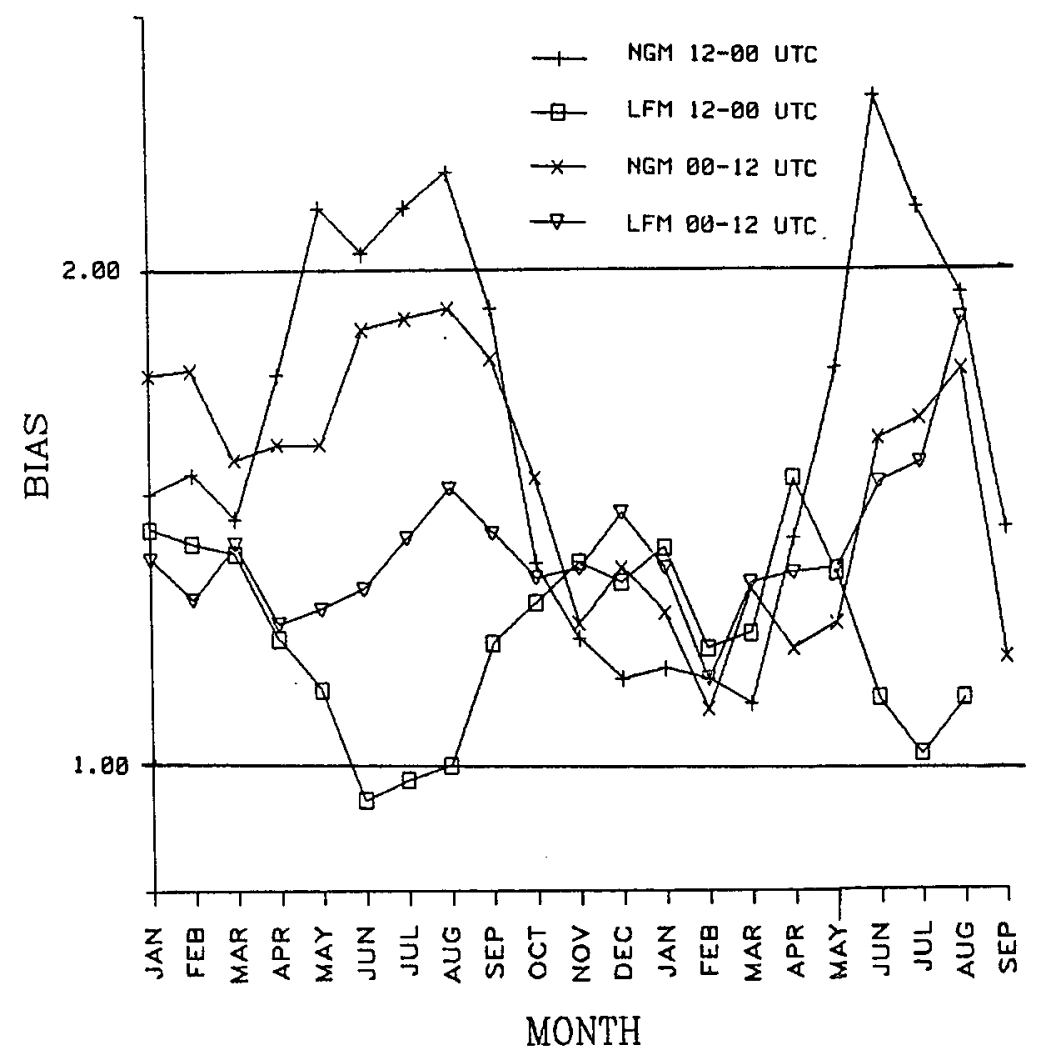

FIG. 15. The $24-36-\mathrm{h}$ bias for $\geqslant 0.01$ in. precipitation during the $21-$ month period from January 1987-September 1988 from a 60-station network evenly distributed over the 48 contiguous states. Bias is plotted for the LFM and NGM for the daytime and nighttime halves of the day.

generate precipitation and underforecast amounts during the first $6 \mathrm{~h}$. The NGM underforecast the total precipitation by over $50 \%$ in the first $6 \mathrm{~h}$, but the amounts increased during the forecast to reasonable values by $24 \mathrm{~h}$. By contrast, the LFM was much too dry at $6 \mathrm{~h}$ but was too wet thereafter. After $24 \mathrm{~h}$, the LFM was too wet by about $50 \%$.

The accuracy of model forecasts depends on the amount being considered. Jensenius found for the cool season that the NGM produced about the right amount of areal coverage for amounts $\leqslant 0.10 \mathrm{in}$., but underestimated the areal coverage for $\geqslant 0.50 \mathrm{in}$. by over $50 \%$. On the other hand, the LFM overforecast areal coverage for precipitation amounts $\geqslant 0.01$ and $0.50 \mathrm{in}$. (Figure 16b shows the observed and forecast frequency of precipitation amounts $\geqslant 0.50$ in.) Thus, for the cool season studied, the NGM significantly underforecasted heavy precipitation while the LFM, on average, overforecasted it.

The results are much different during the summer. The NGM overforecast the areal coverage of measurable precipitation (i.e., amounts of at least 0.01 in.), sometimes doubling the areal coverage from the observed (Fig. 15). For amounts of $\geqslant 0.50$ in., however, the NGM bias was very close to 1 (Fig. 4). In contrast, the LFM underforecast the areal coverage of $\geqslant 0.50$ in. by about $50 \%$.

On an annual basis, NGM threat scores for $\geqslant 0.01$ in. were slightly lower, on average, than those of the LFM, but not significantly so. For amounts $\geqslant 0.50$ in., however, the NGM was clearly the winner during the period April 1987-March 1988 with $12-36$ h precipitation forecasts originating at 0000 UTC having a threat score of 0.24 vs 0.21 for the LFM, and 24-48$\mathrm{h}$ precipitation forecasts originating at 1200 UTC having a threat score of 0.20 vs 0.16 . Most of the NGM's advantage is built during the summer season. During winter the two models score about the same (Fig. 5).

Both the NGM and LFM greatly underforecast amounts in excess of 2 in. per day. Although the models are capable of forecasting many of the atmosphericflow features associated with heavy rainfall events, they rarely explicitly forecast the heavy amounts that create local forecast problems.

\section{3) PRECIPITATION FORECASTING BY SYNOPTIC RE- GIME AND GEOGRAPHICAL REGION}

As mentioned in section $2 \mathrm{c}$, the investigation by Brody indicated that the precipitation amounts pre- 
(a)
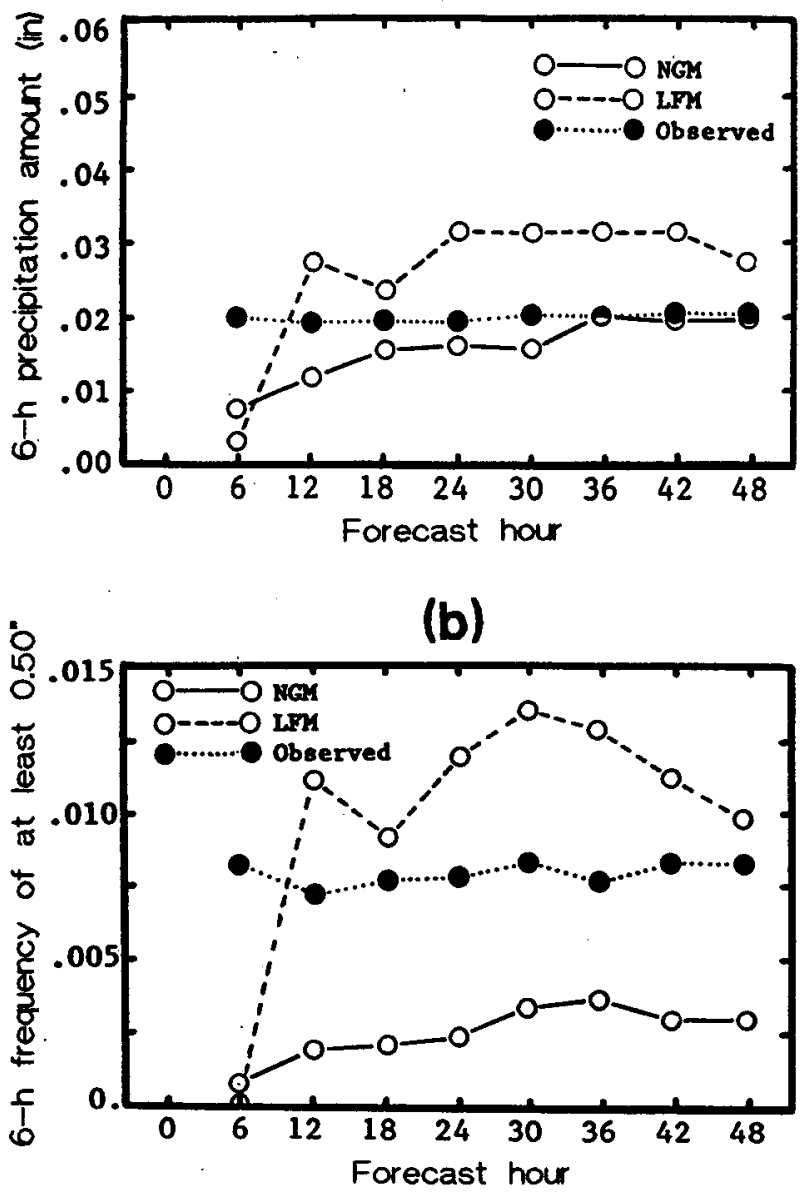

FIG. 16. Comparison of (a) the observed and forecast 6-h precipitation amount for the LFM and NGM, and (b) the observed and forecast frequency of at least $0.50 \mathrm{in}$. All forecasts originate from 0000 UTC for the period 22 October 1987-31 March 1988 and are verified at 230 stations in the contiguous United States. The precipitation amounts and frequencies are for the 6 -h period preceding the respective forecast hour. The precipitation amount is the average over the 230 stations (from Jensenius 1989).

dicted by the NGM were superior to amounts forecast by LFM or AVN/MRF when the associated $500-\mathrm{mb}$ trough was positively tilted. The NGM usually correctly limited the northward extent of the heavier precipitation, whereas the LFM and AVN/MRF often did not. With a $500-\mathrm{mb}$ closed low or trough of negative tilt, however, the LFM was usually correct in allowing the more northward spread of precipitation.

The NGM has a problem forecasting heavy amounts of precipitation in the southern United States during the cool season. Forecasters at NMC have noticed that the NGM is much more likely to underforecast the number of events with $>0.50 \mathrm{in}$./ day when the event is near the Gulf of Mexico than when it is farther north, especially when moderate to strong Gulf inflow is present. An ongoing study of 35 NGM forecasts during the cold seasons of $1987 / 88$ and $1988 / 89$ by the first author supports these observations. The cases were restricted to those with at least $8 \mathrm{mb}$ of gradient in the mean-sea-level pressure between Tallahassee, Florida, and Corpus Christi, Texas. The areal coverage for precipitation amounts of at least 0.50 in. was examined at three different latitudes: $32^{\circ} \mathrm{N}, 36^{\circ} \mathrm{N}$, and $40^{\circ} \mathrm{N}$. Precipitation areas $>166 \mathrm{~km}\left(1.5^{\circ}\right.$ lat $)$ in diameter on the high-resolution analysis of Nierow (1985) were compared to the 24-48-h quantitative precipitation forecasts of the NGM. The NGM failed to forecast 12 of 35 cases at $32^{\circ} \mathrm{N}$. At $36^{\circ} \mathrm{N}$, the number of missed forecasts dropped to five times in 31 cases. The number was only one case in 20 at $40^{\circ} \mathrm{N}$. Thus, the NGM was more apt to underforecast moderate-to-heavy precipitation in the Deep South than in the Ohio Valley. The problem may be related to shortcomings in the model's convective precipitation parameterization, problems in the prediction of the synoptic-scale flow as a result of the nearness of the southern United States to the southern boundary of the model, or the moisture analysis over the Gulf of Mexico.

The same 35 cold-season cases were used to determine whether the NGM was fast or slow in forecasting precipitation amounts of at least $0.50 \mathrm{in}$./day in the southeast United States. The leading edge and the back edge of forecast and observed areas of at least $0.50 \mathrm{in./}$ day were determined at $32^{\circ}, 36^{\circ}$, and $40^{\circ} \mathrm{N}$. One of five different categories was assigned as follows for both the leading and back edges: 1) much too slow-when the forecast edge of precipitation lagged the observed by $>444 \mathrm{~km}, 2$ ) too slow-when the forecast edge of precipitation lagged the observed by $222-444 \mathrm{~km}, 3$ ) well forecast-when the forecast edge was within 222 $\mathrm{km}$ of the observed, 4) too fast-when the forecast edge was $222-444 \mathrm{~km}$ east of the observed, and 5) much too fast-when the forecast was over $444 \mathrm{~km}$ east of the observed. Though most areas with at least $0.50 \mathrm{in}$. of precipitation were generally forecast within $222 \mathrm{~km}$ of the observed position, the leading and back edges were too slow more times than too fast at all the latitudes studied.

Very heavy amounts of precipitation ( $>3.00$ in./ day) were observed 17 times in the 35 cases mentioned above, with the maxima occurring over the lower Mississippi or Tennessee valleys. Of these 17 heavier events, the 24-48 h NGM precipitation forecasts never exceeded the observed maxima. In most cases, the maxima were underforecast by at least a factor of 2 . In extreme cases, a factor of 10 was noted. It was also found that, when the NGM did forecast very heavy rainfall, the model seldom overforecast the amounts. These results are consistent with those of Jensenius (1989), who found that the NGM underforecast the rainfall amounts observed across the southern United States during December 1987-February 1988. A 3month total precipitation of over $16 \mathrm{in}$. was observed in two separate areas, one over southeastern Louisiana 
and the other extending from Arkansas to extreme southern Illinois. The $0-24 \mathrm{~h}$ forecasts by the NGM showed a maximum over northeast Arkansas of only 8 in.

\section{g. Summary of NGM performance}

The NGM is generally superior to the LFM. The NGM's greater horizontal and vertical resolution, as well as more realistic physical processes, allow better delineation of such features as fronts, surface lows, and dry lines. Like all numerical models, the NGM has a number of strengths and weaknesses, which are listed below.

\section{Strengths:}

1) The NGM is better than the LFM at forecasting geopotential height at most levels.

2) The NGM is better than the LFM at forecasting temperature at most pressure levels, as measured by the mean temperature error. The standard deviation of the temperature errors for the NGM is less than those for the LFM above $500 \mathrm{mb}$.

3) The NGM is more accurate than the LFM at forecasting the position of cyclones and anticyclones.

4) The NGM is very useful in forecasting explosive cyclogenesis.

5) The NGM is better than the LFM at forecasting heavy precipitation in the warm season.

6) The NGM is often better than the LFM at forecasting heavy precipitation when a 500-mb trough has a positive tilt.

\section{Weaknesses:}

1) The NGM has an unexplained cold bias over the Rocky Mountains and a warm bias over the eastern United States.

2) The NGM has problems handling Arctic air masses.

3) The NGM overdeepens surface cyclones over land and underdevelops them over oceans.

4) The NGM forecasts of surface cyclones over the eastern half of the contiguous United States are, on average, too far northwest. Surface cyclones are forecast too far north in the western contiguous United States, but there is very little mean directional error for the northern half of North America.

5) The NGM slightly overforecasts the strength of anticyclones over the western contiguous United States.

6) The NGM overforecasts the strength of sea and lake breezes, with an associated overprediction of precipitation.

7) The NGM overforecasts light precipitation during the summer.

8) The NGM underforecasts heavy precipitation during winter, especially near the Gulf of Mexico.

9) The NGM is often worse than LFM in forecasting precipitation during the winter when the $500-\mathrm{mb}$ trough is negatively tilted.

\section{Conclusions}

While the LFM offers forecasters a first glimpse at how weather systems might evolve, the higher-resolution NGM, on the whole, is more accurate, especially in forecasting the positions of cyclones, anticyclones, and the advection patterns that determine where and when precipitation will occur. The NGM's resolution and more advanced modeling of physical processes contribute to the prediction of much more realistic and well-defined features such as surface lows, fronts, and upper-level jets. Even its resolution, however, is not enough to simulate properly some features such as the sea breeze and the diurnal cycle in anemometer-level winds.

The LFM forecast model was last changed in January 1985. Development of the LFM was discontinued for several reasons, including the devotion of resources to NGM development and the desire not to degrade the performance of MOS. The LFM analysis continues to improve a little as the result of improvements to the Global Data Assimilation System, which provides the first guess for the analysis.

Work is underway to reduce some of the deficiencies in the NGM. Improvements being tested include upgrading the specification of subsoil temperature, which effects low-level temperature forecasts; adding several more layers near the surface of the earth and at jet level; increasing the horizontal resolution of the terrain field; replacing the snow and ice cover analysis with one that has higher horizontal resolution, is updated daily, and includes snow depth; reducing errors in the motion of weather systems by increasing the accuracy in calculating horizontal gradients; and using an alternate moist convection method.

Acknowledgments. The authors are grateful to John Jensenius, Dennis Keyser, Anthony Mostek, David Olson, and Ralph Petersen for providing many of the figures, and to Frank Brody, Paul Dorian, and an anonymous reviewer for their very helpful suggestions and ideas. Special thanks are due the Weather and Forecasting editors Louis Uccellini and Paul Kocin for their untiring efforts to make this article and the entire special NMC issue possible.

\section{REFERENCES}

Caplan, P. M., and G. H. White, 1989: Performance of NMC's medium range model. Wea. Forecasting, 4, 391-400.

Carr, F. H., R. L. Wobus and R. A. Petersen, 1989: Normal mode initialization experiments with the NMC nested grid model. Mon. Wea. Rev., in press.

Carter, G. M., J. P. Dallavalle and H. R. Glahn, 1989: Statistical forecasts based on NMC's numerical prediction system. Wea. Forecasting, 4, 401-412.

Deaven, D. G., 1985: New stress formulation for the LFM. Technical Procedures Bulletin 348, National Weather Service (NOAA), $6 \mathrm{pp}$. [Available from the Office of Meteorology, National Weather Service, W/OM23, Room 1313 Gramax, 8060 13th Street, Silver Spring, MD 20910.]

Donaldson, R. J., R. M. Dyer and M. J. Kraus, 1975: An objective evaluator of techniques for predicting severe weather events. 
Preprints, Ninth Conference on Severe Local Storms, Amer. Meteor. Soc., Norman, Oklahoma, 321-325.

Dorian, P., 1983: Interactive use of minicomputer capabilities in assessing short-term humidity forecasts by the LFM-II model. Master's Thesis, Dept. of Meteorology, The Pennsylvania State University, $84 \mathrm{pp}$. [Available from Dept. of Meteorology, 503 Walker Building, University Park, PA 16802.]

Grumm, R. H., and J. R. Gyakum, 1986: Systematic surface anticyclone errors in NMC's limited-area fine-mesh and spectral models during the winter of 1981/82. Mon. Wea. Rev., 114, 2329-2343.

— NMC's nested grid model, November 1988 through January 1989. Wea. Forecasting, 4, 246-252.

Hoke, J. E., 1987: Improving the horizontal resolution of the nested grid model. Technical Procedures Bulletin 368, National Weather Service (NOAA), 9 pp. [Available from the Office of Meteorology, National Weather Service, W/OM23, Room 1313 Gra$\max , 8060$ 13th Street, Silver Spring, MD 20910.]

- , N. A. Phillips, G. J. DiMego, J. G. Sela and D. G. Deaven, 1985: NMC's Regional Analysis and Forecast System-Results from the first year of daily, real-time forecasting. Preprints, Seventh Conference on Numerical Weather Prediction, Amer. Meteor. Soc., Montreal, 444-451.

$-,-\ldots,-$ J. J. Tuccillo and J. G. Sela, 1989: The Regional Analysis and Forecast System of the National Meteorological Center. Wea. Forecasting, 4, 323-334.

Jensenius, J. S., 1989: A statistical comparison of the forecasts produced by the NGM and LFM for the cool season of 1987-88. TDL Office Note 89-4, Techniques Development Laboratory, National Weather Service (NOAA). [Available from Techniques Development Laboratory, Room 825 Gramax, 8060 13th Street, Silver Spring, Maryland 20910.]

Junker, N. W., 1985: Recognizing characteristic model errors and incorporating them into precipitation forecasts. Preprints, Sixth Conference on Hydrometeorology, Amer. Meteor. Soc., Indianapolis, $270-276$.

Kanamitsu, M., 1989: NMC's global spectral model and Global Data Assimilation System. Wea. Forecasting, 4, 335-342.

Keyser, D. A., G. H. White and J. H. Ward, 1988a: NMC seasonal performance summary, December 1987-February 1988. National Meteorological Center, National Weather Service (NOAA), 58 pp. [Available from Development Division, National Meteorological Center, Room 204 World Weather Building, Washington, DC 20233.]

- and $-1988 \mathrm{~b}$ : NMC seasonal performance summary, March-May 1988. National Meteorological Center, National Weather Service (NOAA), 74 pp: [Available from Development Division, National Meteorological Center, Room 204 World Weather Building, Washington, DC 20233.]

Nierow, A., 1985: The National Meteorological Center's automated objective 24-hour precipitation analysis. Preprints, Seventh Conference on Numerical Weather Prediction, Amer. Meteor. Soc., 17-20 June 1985, Montreal, P.Q., Canada, 38-42.
Petersen, R. A., 1988: Evaluating systematic performance characteristics of RAFS mid- and low-level forecast fields. Preprints, Eighth Conference on Numerical Weather Prediction, Amer. Meteor. Soc., 22-26 February 1988, Baltimore, 839-843.

- - and J. E. Hoke, 1989: The effect of snow cover on RAFS lowlevel forecasts. Wea. Forecasting, 4, 253-257.

- and J. D. Stackpole, 1989: An overview of the NMC production suite. Wea. Forecasting, 4, 313-322.

Phillips, N. A., 1986: Turbulent mixing near the grourd for the nested grid model. Office Note 318, National Meteorological Center, National Weather Service (NOAA), 19 pp. [Available from Development Division, National Meteorological Center, Room 204 World Weather Building, Washington, DC 20233.]

1987: Temperature calculations in the nested grid model. Technical Procedures Bulletin 373, National Weather Service (NOAA), $8 \mathrm{pp}$. [Available from the Office of Meteorology, National Weather Service, W/OM23, Room 1313 Gramax, 8060 13th Street, Silver Spring, MD 20910.]

- 1988: The effects of turbulent mixing near the ground in the nested grid model. Office Note 340, National Meteorological Center, National Weather Service (NOAA), 25 pp. [Available from Development Division, National Meteorological Center, Room 204 World Weather Building, Washington, DC 20233.]

- J. J. Tuccillo and J. E. Hoke, 1988: The impact of less frequent calculations of vertical austausch and precipitation on forecasts from the nested grid model. Office Note 337, National Meteorological Center, National Weather Service (NOAA), 14 pp. [Available from Development Division, National Meteorological Center, Room 204 World Weather Building, Washington, DC 20233.]

Richwien, B. A., 1980: The damming effect of the southern Appalachians. Natl. Wea. Dig., 5, 2-12.

Sanders, F., 1986: Explosive cyclogenesis in the west-central North Atlantic Ocean, 1981-1984; evaluation of LFM model performance. Preprints, Eleventh Conference on Weather Forecasting and Analysis, Amer. Meteor. Soc., 17-20 June 1986, Kansas City, 57-61.

- 1987: Skill of NMC operational models in prediction of explosive cyclogenesis. Wea. Forecasting, 2, 322-336.

-_- and E. P. Auciello, 1989: Skill in prediction of explosive cyclogenesis over the western North Atlantic Ocean, 1987-1988: A forecaster checklist and NMC dynamical models. Wea. Forecasting, 4, 157-172.

Shuman, F. G., and J. B. Hovermale, 1968: An operational six-layer primitive equation model. J. Appl. Meteor., 7, 525-547.

Silberberg, S. R., and L. F. Bosart, 1982: An analysis of systematic errors in the NMC LFM-II model during the 1978-1979 cool season. Mon. Wea. Rev., 110, 254-270.

Tuccillo, J. J., and N. A. Phillips, 1986: Modeling of physical processes in the nested grid model. Technical Procedures Bulletin 363, National Weather Service (NOAA), Silver Spring, Maryland, $24 \mathrm{pp}$. [Available from the Office of Meteorology, National Weather Service, W/OM23, Room 1313 Gramax, 8060 13th Street, Silver Spring, MD 20910.] 